Portland State University

PDXScholar

1975

\title{
An Analysis of the Effects of Individual Counseling and Group Process Techniques Upon the Behavior of Children in a Juvenile Detention Facility
}

Robert Arthur Struble

Portland State University

Follow this and additional works at: https://pdxscholar.library.pdx.edu/open_access_etds

Part of the Child Psychology Commons, and the Counseling Psychology Commons Let us know how access to this document benefits you.

\section{Recommended Citation}

Struble, Robert Arthur, "An Analysis of the Effects of Individual Counseling and Group Process Techniques Upon the Behavior of Children in a Juvenile Detention Facility" (1975). Dissertations and Theses. Paper 2240.

https://doi.org/10.15760/etd.2237

This Thesis is brought to you for free and open access. It has been accepted for inclusion in Dissertations and Theses by an authorized administrator of PDXScholar. Please contact us if we can make this document more accessible: pdxscholar@pdx.edu. 
AN ABSTRACT OF THE THESIS OF Robert Arthur struble for the

Master of Science in Poychology presented July 24, 1975.

Titlos An Analysis of the Effects of Individual Counseling

and Group Process Techniques Upon the Behavior of

Children in a Juvenile Detention Facility.

APPROVED BY MEMBERS OF THE THESTS COMMITTEE:

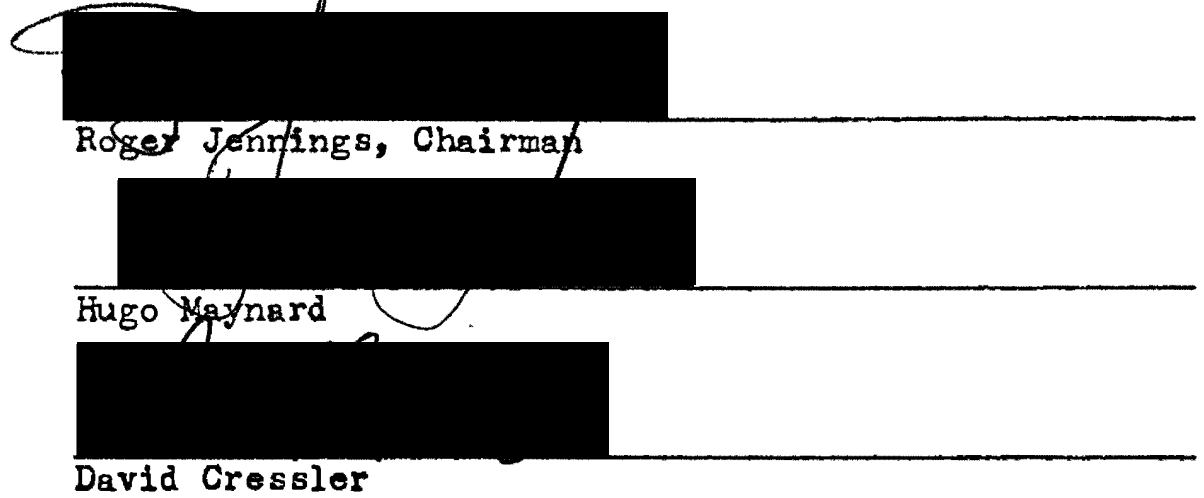

A three month project was designed to study the effects of individual counseing combined with group process techniques upon the behavior of children in a short term detentional facility. The length of stay was also a primary variable in the study of this behavior.

The behavior of 282 males, 14 to 17 years of age, whom had been admitted to the jurenile detention facility in Portland, Oregon, was analyzed via throe separate instruments. The Bohavior Activity Inventory was utilized to obtain daily observations concerning four separate areas of interest. An attitudinal rating scale was devised to obtain the staff's assessment as to the effects of the study. A questionnaire was utilized in evaluating the children's opinions regarding the study. 
The subjects were randomly assigned to one of three treatment groups: Control, Social Interaction, and Detention Counseling. The control group was subjected to the group process approach that existed in the facility prior to the study. The Social Interaction Group was assigned a detention counselor in addition to receiving the standard group process approach. The counselor of this group merely showed the child some individual attention and avoided an actual counseling type relationship. The counseling group was similar in nature to the social interaction group, however, standardized counseling techniques were used whth this group. Length of stay was analyzed in reference to three separate groups: Those detained 1 to 6 days, those detained 7 to 14 days, and those detained for more than 2 weeks.

Analysis of the data obtained from the questionnaire indicated that the children viewed the combination of the two approaches, regardless of whether or not they were "counseled", as being more helpful. Children detained less than two weeks saw counseling as more beneficial than merely social interaction. Analysis of the rating scales done on each subject by staff indicatied that there was no significant change in behavior as a result of either the treatment or diagnostic variables. Information from the daily observation showed significant reductions in the amount of negative behavior for the children in the two "counseling" groups as compared to the control group. No significant differences were indicated on the remaining three items of that instrument. Analysis according to length of stay resulted in increased levels of disciplinary restriction and increased levels of social interaction with increased length of stay. The amount of negative behavior elicited also reached higher levels with an increased length of stay. 
AN ANALYSIS OF THE EFFECTS OF INDIVIDUAL COUNSELING AND GROUP PROCESS TECHNIQUES UPON THE BEHAVIOR OF CHILDREN IN A JUVENIIE DETENTION FACILITI

\author{
by \\ ROBERT ARTHUR STRUBLE
}

A thesis submitted in partial fulfillment of the requirements for the degree of

\title{
MASTER OF SCIENCE \\ in \\ PSYCHOLOGY
}

\author{
Portland State University
}

1975 
TO THE OFFICE OP GRADUATE STUDIBS AND RESEAROH

The members of the Comittee approve the thesis of

Robert Arthur struble prosonted July 24, 1975.
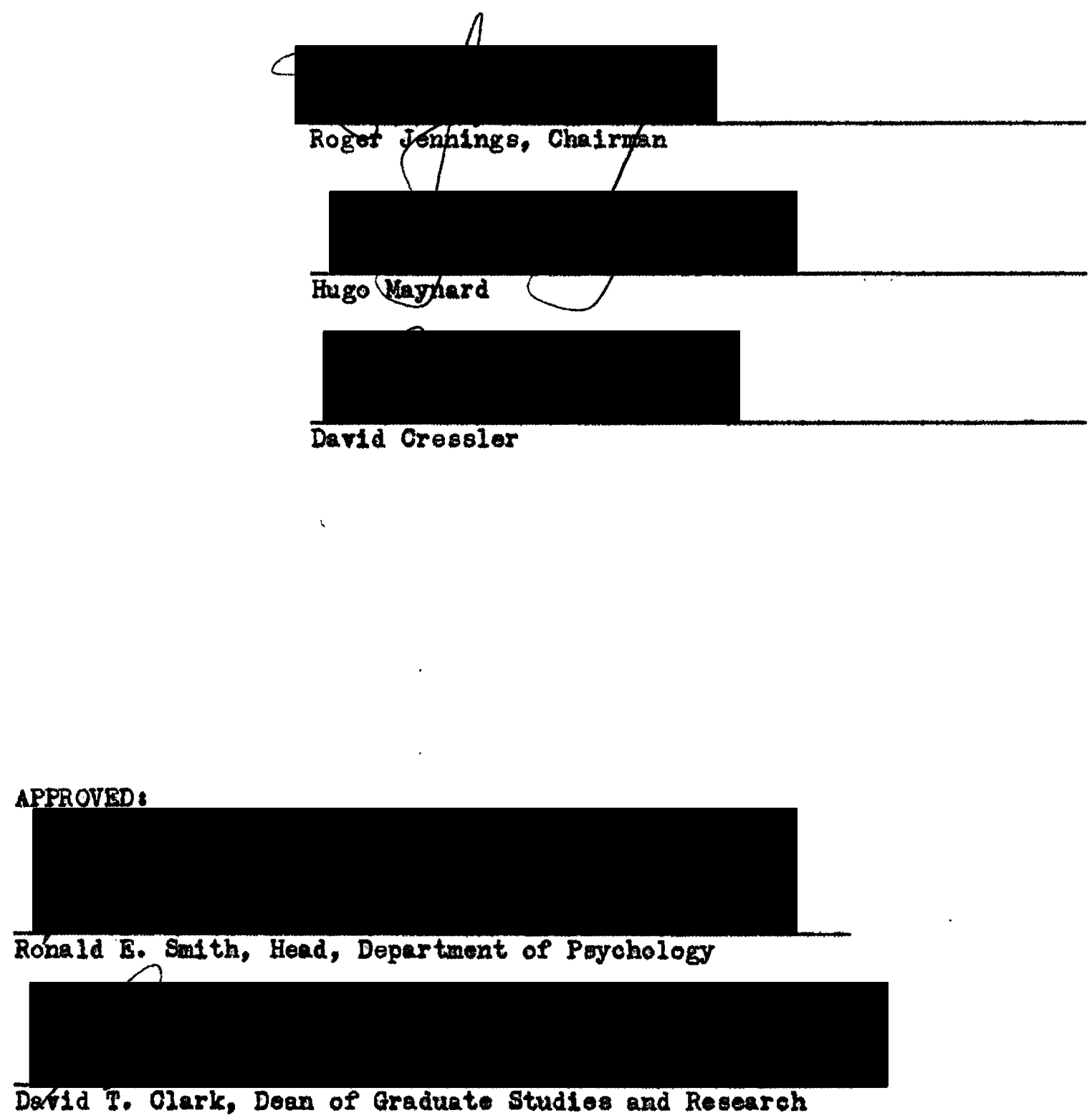

July 24, 1975 
TABIE OF CONTENTS

PAGE

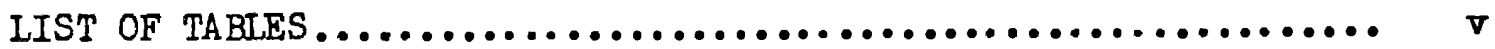

IIST OF FIGURES................................. Ix

INTRODUCTION $\ldots \ldots \ldots \ldots \ldots \ldots \ldots \ldots \ldots \ldots \ldots \ldots \ldots \ldots \ldots \ldots \ldots \ldots \ldots \ldots \ldots \ldots \ldots$

Detention Homes................................ I

Therapy vs Control.............................. 3

Group Counseling vs Individual Counseling............. 5

Methods of Evaluation............................ 7

General Hypothesis............................. 7

METHODS............................................

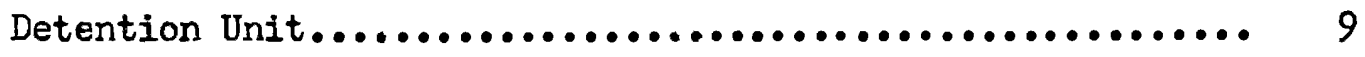

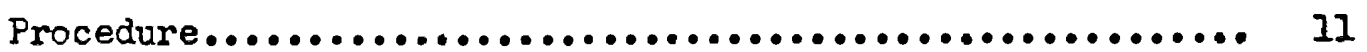

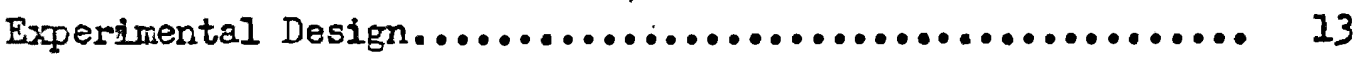

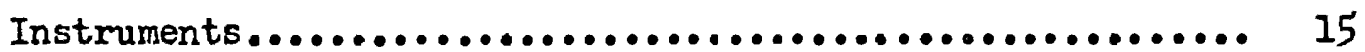

Instrument \#1

Instrument \#2

Instrument \#3

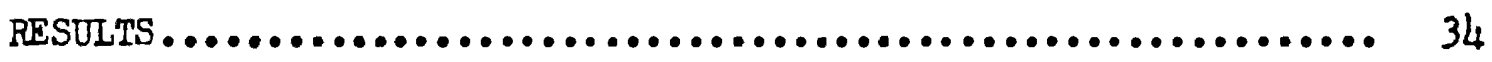

Behavior Activity Inventory....................... 34

Attitudinal Rating Scale......................... 42

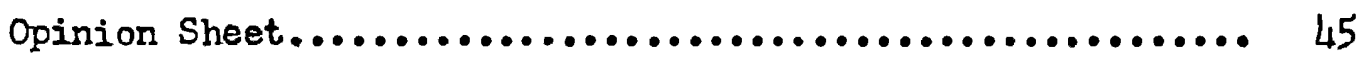


PAGE

DISGUSSION AND CONCLUSIONS......................... 52

Length of stay................................ 56

Behsvior Control.............................. 57

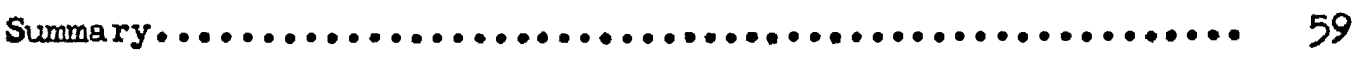

BIBLIOGRAPHY..................................... 61

APPENDIX........................................ 66 
LIST OF TABLES

TABIE

PAGE

I Subject distribution among groupworkers for the two

counseling group ${ }^{\star} \ldots \ldots \ldots \ldots \ldots \ldots \ldots \ldots \ldots \ldots \ldots \ldots . \ldots \ldots$

II Distribution of S's among the "treatment" and "diag-

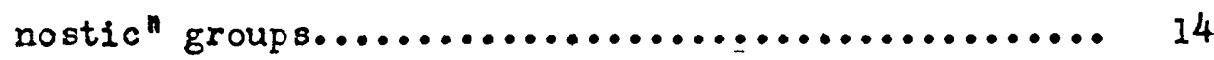

II Average $\%$ of Inter-Rater Reliability prior to study..... 21

IV Average \% of Inter-Rater Reliability midway through

the project............................... 22

$V$ Number of subjects involved in B.A.I. observations in each of the three "diagnostic" groups for the three

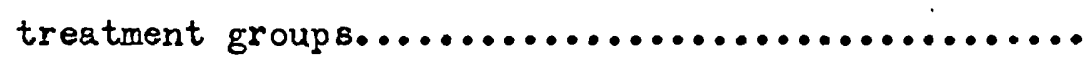

VI Number of subjects involved in the attitudinal rating scale in each of the three "diagnostic" groups for

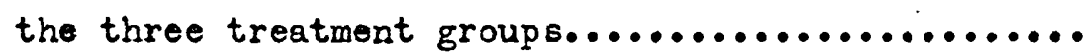

VII Number of subjects involved in filling out the Opinion Sheet Questionnaire in each of the three "diagnostic" groups for the three treatment groups............ 32

VIII Mean scores of each of the treatment and "diagnostic" groups on the Social Activity scores obtained from the Behsior Activity Inventory................ 36

IX Results of the $3 \times 3$ ANOVA with unequal groups for the Social Activity scores at the .05 level of significance.................................... 
X Results of a multiple range test with unequal groups applied to the differences between "diagnostic" means obtained from the Social Activity scores of the Behavior Actirity Inventory. Tested at .05 level of significance....................... 38

XI Mean scores for each of the treatment and "diagnostic" groups on the Freedom of Movement scores obtained from the Behavior Activity Inventory.

XII Results of the $3 \times 3$ ANOVA with unequal groups for the Freedom of Movement scores of the Behavior Activity Inventory. Statistical significance tested at the .05 level.................................

XIII Results of a multiple range test with unequal groups applied to the differences between "diagnostic" means obtained from the Freedom of Movement scores of the Behavior Activity Inventory. Tested at .05 level of significance.............................. 40

XIV Mean scores for each of the treatment and "diagnostic" groups on the Negative Behavior scores obtained from the Behavior Activity Inventory................. 40

XV Results of the $3 \times 3$ ANONA with unequal groups for the Negative Behavior scores of the Behavior Activity Inventory tested at the .05 level of significance........ 4] 
XVI Results of a multiple range test with unequal groups applied to the differences between the "diagnostic" means and between treatment means obtained from the Negative Behavior scores of the Beharior Activity Inventory. Tested at .05 level of significance...................................

XVII Mean acores of Attitudinal Rating Scale obtained at time of admission.

XVIII Outcome of a $3 \times 3$ ANOVA with unequal groups on the mean scores obtained on the initial Attitudinal Rating Scale. Level of signiflcance tested was .05....... 43

XIX Mean scores of Attitudinal Rating Scale obtained at time of release................................ 44

$\mathrm{XX}$ Outcome of a $3 \times 3$ ANOVA with unequal groups on the mean scores obtained on the final attitudinal Rating Scale. Tested at the .05 level of aignificance........... 44

XXI Mean scores obtained from Question No. 2 of the Opinion Sheet.

XXII Resulta of a $3 \times 3$ ANOVA performed on the mean scores obtained from Question No. 2 of the Opinion Sheet..... 47 XXIII Results of a multiple range test with unequal groups applied to the differences between "diagnostic" means and between treatment means obtained via Question No. 2 of the Opinion Sheet. 
TABLE

PAGE

XXIV Kean scores obtained via Question No. 3 of the Opinion Sheet.

XXV Outcome of the $3 \times 3$ ANOVA performed on the mean scores

obtained from Question No. 3 of the Opinion Sheot... 49

XXVI Results of a multiple range test with unequal groups

applied to the differences between "diagnostic"

means and between trestment means obtained via

Question No. 3 of the Opinion Sheet............... 49

XXVII Mean scores obtained from Question No. 4 of the Opinion

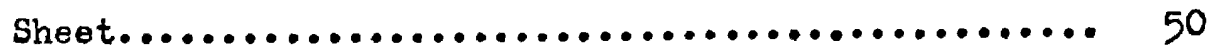

XXVIII Outcome of $2 \times 3$ ANOVA utilizing meen scores from Question

No. 4 of the Opinion Sheet.................... 51 
LIST OF FIGURES

FIGURES

PAGE

1 Illustration of mean scores of each of the treatment and "diagnostic" groups on the Social Activity Scores obtained from the Behavior Activity Inventory

2 Illustration of the mean scores for each of the treatment and "diagnostic" groups on the Freedom of Movement scores obtained from the Behavior Activity Inventory $\ldots \ldots \ldots \ldots \ldots \ldots \ldots \ldots \ldots \ldots \ldots \ldots \ldots \ldots \ldots \ldots$

3 Illustration of the mean scores for each of the treatment and "diagnostic" groups on the Negative Behavior scores obtained from the Behavior Activity Inventory

4 Illustration of the mean scores obtained from Question No. 2 of the Opinion Sheet.................. 46

5 Illustration of the mean scores obtained via Question No. 3 of the Opinion Sheet.................... 48 6 Illustration of the mean scores from Question No. 4 of the Opinion Sheet. 


\section{INTRODUCTION}

"The detention of children and youth awaiting court hearings has been one of the most neglected areas in the correctional field."

The above quote is the opening line from the Standards \& Guides for the Detention of Children \& Youth (National Council on Crime \& Delinquency, 1961). Unfortunately, this statement of fact still holds true today (Ohlin, 1973; Sagarin \& NacNamara, 1973; Smith \& Berlin, 1974 ). It is amazing that such a condition exists when one considers that there are approximately 250 such institutions in the United States dealing with thousands of children each year (Fox, 1972). Most of these children are held without the opportunity for bail and without some of the due processes of law offered the adult criminal (Carter, Glasser, \& Wilkins, 1972; U.S. Dept. of Justice, 1973); the most recent trend is to provide alternatives to detention, however, most writers agree that delinquent children who are a serious threat to themselves or society do require such a facility (Bakal, 1973; Breed, 1972; Coffey, 1974). It is to this type of child and to this type of institution that the present thesis addresses itself.

\section{Detention Homes}

Detentional institutions differ from state training schools, group homes, and other types of juvenile institutions on two primary factors (Amos \& Mazella, 1965). The first issue involves the purpose. Detention is primarily a holding center, while the main purpose of other institutions centers around behavior change. The second issue is that of length of stay. Detentional facilities tend to be for short term confinement 
(30 days or less) as opposed to long term stays ( 90 days or more) in other institutions.

Detention homes are rarely found in cities with a population of less than 50,000. Smaller cities and towns generally house children in the city or county jail if it should become necessary (Fox, 1972).

A typical definition of children who require care in a detention home is: "Those children whose behavior, condition, or circumstances are such to endanger their welfare, the welfare of others, or pose a threat to the community" (Multnomah County Juvenile Court Manual, 1973).

Initial decisions to house a child in a detention home are made by an employee of the juvenile court (intake worker) after a referral is made by the police, parents, another agency, or the child. In many jurenile courts a permanent decision regarding housing is made the following day by a judge or referee. The more progressive institutions tend to divert the child if possible or release the child at the first opportune moment. Diversion from such institutions is a definite trend established in recent years (Adams, Carter, Gerletti, Pursuit, \& Rogers, 1973; U.S. Dept. of Justice, 1973).

Detention homes are generally a branch of and function under the administration of the juvenile court. In theory, the central purpose of the detentional facility is to house children until they are brought to a formal hearing. Each child referred to the juvenile court is assigned to an individual, commonly referred to as a Counselor or Probation Officer. This individual decides whether the case is closed, placed on probation, taken to a formal hearing or disposed of by some other appropriate action. Generally speaking, a very smail percentage of a counselor's caseload will be in detention at any given time. Typically, a child's release from 
detention is dependent upon a decision by the child's counselor or the Juvenile Court judge.

\section{Therapy vs Control}

When evaluating programs used in juvenile institutions a distinction must be drawn between "therapy" or "treatment" and "behavior control." Amos \& Manella (1965) provide an excellent description of what is meant by "control" when dealing with juveniles in an institutional setting. In this paper, control means minimizing aggressive, negative, acting out behavior, in a manner that produces a healthier and less damaging experience for the child.

It is easy to see how these issues are confused when one looks at how "correctional treatment" is sometimes defined: "Any activity other than investigation, surveillance, or supervision in which the probation officer, counselor, or parole agent engages with the client for the sole purpose of rehabilitation" (Coffey, 1974). Such definitions of "correctional treatment" or "therapy" confound the distinction between therapy and control.

There is a wealth of data dealing with "therapy" or "treatment" programs in long term institutions (Coffey, 1974; Cull \& Hardy, 1973; Gibbons, 1965; Lewis, 1972; PIlnich \& Neale, 1966; Robinson, 1960; Smith \& Berlin, 1974). Data addressing the issue of "therapy" in the short term facilities, however, are at best minimal (Adams, et al, 1973; Sagarin \& MacNamara, 1973). A reading of these studies suggests that treatment in short term institutions is often confused with behavior control. When discussing their "program" most detention home administrators speak in terms of "therapy" and "treatment" with little regard to the "control of 
behavior" (Amos \& Manella, 1965). Historically detention home programs have been modeled after the treatment programs used in long term facilities (Robison, 1960). By nature and necessity the long term facilities emphasize treatment and rehabilitation in their programs. It may be that the needs of detention homes are not met by these programs. In fact, if It is assumed that control should precede treatment, then the behavior control programs developed in detention homes would be modeled by the long term institution. In actuality, the literature reveals a lack of empirical research regarding the development or evaluation of detention home programs (Adams, Carter, Gerletti, Pursuit, \& Rogers, 1973). Several reasons have been proposed to account for the shortage of research: 1) The lack of judicial and administrative co-operation (Quay, 1965); 2) Iack of qualified staff (Caven, 1962); and 3) Shortness of stay does not lend itself to study (Robison, 1960).

It is herein proposed that control rather than treatment is of primary concern in a detentional facility. Furthermore, it is proposed that control should precede treatment in an institution and that treatment is not feasible without first establishing proper behavioral controls. Finally, issues of control may be of primary importance to the long term institutions as well (Bigelow, 1973).

\section{Group Counseling vs Individual Counseling}

The principal modes of therapy found when working with delinquent children, both in and out of institutions, are individual and group counseling (American Correctional Association, 1973; Averill, Cadman, Craig, EIinden, 1973; Lewis, 1972). Juvenile courts over the United States tend to rely most heavily upon an individual counseling basis, whereas, "Iong term" institutions tend to emphasize the group approach (Carter, Glasser, 
and Wilkins, 1972; Hardy \& Cull, 1973). Detention homes tend to adhere more closely to the "group counseling" methods typically involving ouch aspects of group process as group discussions, paychodrame and role playing. An excellent description of "group counseling" or "group process" approach as used in a juvenile institution is offered by Averill, Cadman, Craig, \& Indon (1973).

"Individual counseling" defles a precise definition. Approaches to this method appear to be quito eclectic in that they vary widely from individual to individual and from court to court (Fox, 1972). The range is from "informal chats" to long-term psychoanalytical approaches. There does not appear to be a standardized approach.

Detention homes generally rely upon the counseling branch of the juvenile court to provide the necessary "individual counseling" while detention staff are responsible for the "group counseling" (Henry, 1972). On-the-job training for dotention staff is usually offered regardless of the particular emphasis or setting if the worker does not possess prior skil1s. There exists a great deal of controversy concerning the relative advantages or disadvantages of these two approaches. Individual and group counseling have both, on occasion, been viewed with a skeptical pessimism, due primarily to a lack of experimentaliy supportive evidence (Adam, et al, 1973; Amos \& Fiellford, 1967; Hardy, 1973; Ohlin, 1973; Wheeler, 1963). St1ll others (Cull \& Hardy, 1973; Draracous, 1954; Gibbons, 1965) uphold the general merits of one or the other, but only with certain types of delinquents. The position that intensive counseling actually promotes delinquency has even been presented (Amos \& Wellford, 1967). Even though there is a mass of contradictory findings regarding methods of "treatment", the majority of evidence supports both individual 
and group counseling methods as effective treatment tools (Averill, et al, 1973; Carter, Glasser, \& Wllkins, 1972; Cavan, 1962; Freeman \& Weeks, 1966; Hardy \& Cull, 1973; MacIver, 1966).

Behavior control data relative to individual and group counseling in juvenile institutions is virtually non-existent (Carter, et al, 1972; Hundal, 1971). It is proposed that behavior control has been a central issue in previous research, but has been studied under the guise of "therapy" and/or "treatment".

It is the position herein that the combined approaches of individual counseling and group counseling should prove more beneficial than either approach used singularly. Furthermore, it is proposed that in respect to behavior control the type of individual counseling utilized is the primary control variable. Finally, issues of different types of individual counseling, relative to behavior control, may be of utmost concern to long term institutions.

\section{Purpose of Study}

This three month study attempts to analyze the effects of combining individual counseling techniques with a group counseling approach. The dependent variable being the degree of anti-social behavior exhibited by juveniles housed in a detention facility. Two separate individual counseling approaches will be incorporated into the ongoing group counseling program of the facility. These two approaches will be compared against one another and to a control group comprising onis of those receiving group counseling. It is proposed that the individual counseling variables w1ll result in less anti-social behavior.

The data will be analyzed in regards to the length of stay in the detention facility. This variable is viewed as being of importance in 
order to generalize the findings to the more prevalent long term institutions.

AII aspects of this study relate to the problem in terms of methods of "behavior control" and are not to be interpreted as methods of "therapy."

\section{Methods of Evaluation}

As indicated previously, the itterature pertaining to behavior control in short term institutions for juveniles is exceedingly sparse. Iikewise, tools needed to study such problems are also lacking (Allen, 1971; Sagarin \& MacNamara, 1973). Various authors (Allen, 1971; Fairweather, 1964; Smith, 1973) have demonstrated innovative methods of studying behavior in institutions, while others promote the great need for better methods of evaluation (Adams, et al, 1973; Carter, et al, 1972). The writer has attempted to devise new methods and adapt existing methods.

Three separate methods of analyzing the problem were used: The writer attempted to obtain information via observations of the children's behavior, assessing attitudes of the staff, and collecting opinions of the children themselves. The rationale for these methods and the method of devising these instruments are presented in the methods section of this thesis.

\section{General Hypothesis}

In following the "group treatment" approach of the longer term institutions, most detention homes rely upon their "counseling" staff for any "individual counseling" that is required during the child's stay in detention. Due to the jurenile court counselor's other responsibilities (other cases, dictation, hearings, etc.) frequently he/she can only allow 
an hour or so per week to the detained child. When one considers that the detentional experience is a child's first introduction to correctional institutions, and his/her first experience of forced withdrawal from the family, it would appear that a higher degree of individualized attention would be needed. Forced group participation, with strangers, in such a facility would seemingly require more "individual counseling" or at least a feeling that there is someone immediately available to whom one could turn. It is proposed that a child is less likely to exhibit negative behavior if someone is immediately available to turn to. Detention staff, as opposed to counseling staff, appeared the logical choice.

It was further felt that although a strong case might be made towards labeling such attention "therapy", that the real issue was "behavior control." "Control" as defined previously, is designed to help the child develop a maximum amount of self control with a minimum amount of coercion.

Another central issue the writer felt to be of concern was that of the length of stay. The relationship of length of stay to individual counseling requires examination in order to generalize the findings to long term institutions. Each of the independent variables were therefore analyzed relative to the number of days detained. It is proposed that the longer a child is exposed to the counseling variables the greater the reduction in anti-social behavior.

In view of the above considerations, the following general hypothesis was derived: Individualized "counseling" by detention home staff will result in less antisoctal behavior exhibited by detainees and the degree of change will vary according to length of stay. 
METHODS

Detention Unit

The standard model for a detention unit in the United States consists typically of a locked and secure unit set up to house and totally care for approximately 20 children. The unit usually consists of: A locked office for staff (centrally located in the ward), living room, game room, kitchen and dining room facilities, several bathrooms, and individual sleeping rooms that are locked at night. Other facilities that are typically provided are: Gymasium, fenced outside playing area, classrooms, medicel office, visiting facilities, and admissions area. The reader is referred to Amos\& Manella (1966) for a more detailed description.

The detention unit in this study was one of seven units of the Donald E. Iong Home provided by Multnomah County in Portland, Oregon. In the last year, however, the home has been reduced to two such units. It is maintained for the purpose of temporarily housing juvenile offenders who are awaiting a court hearing or disposition of their case. The seven detention units ( 4 male and 3 female) are located adjacent to the juvenile court, which houses the juvenile court counselors, administrators, clerical staff, and other supportive staff such as research coordinator, volunteer co-ordinator and so forth.

The staff members of the detention unit utilized in the study were adult males ranging in age from 24 to 28 . There were seven full time staff members, referred to as "children's groupworker", all whom had had 
at least one year's experience in working with children. One of the staff members worked only at night whlle the children were in bed and was, therefore, not involved in the individual counseling aspoct of the project. Five of the staff members, classifled as groupworker II's, were responsible for the day-to-day care of the children in the unit. The remaining staff person, the groupworker III, had the same responsibilities as the groupworker II and, in addition, was responsible for coordinating the overall efforts of the staff in that unit. Prorequisite for all groupworker positions was a bachelor's degree fram an accredited college or university.

The daily program for these children during the week consisted of a full time school schedule during the day and programmed activities, in accordance with the goals of the court, during the afternoon and evening. The school program was operated by teachers from the Portland Public School District No. 1 and was interrupted by meals, gym periods, and freo time in the unit, all of which was supervised by the unit staff (groupworkers). From $3: 30$ p.m. until $10: 00$ p.m. the program was determined by the groupwork staff. It basically consisted of a "group process approech which involved a minimum of four group discussions per week, utilizing psychodrama and role playlng techniques. Recreational programs, movies, co-ed activities, and various craft programs were included in the evening programming. During the week-end the children were completely under the supervision of the groupworkers on duty. While in the detention home children were supervised 24 hours a day. Children were not allowed out of the detention complex without special authorization from the jurenile court counselor.

As mentioned previously, oach child who is detained 18 assigned 
a fuvenile court counselor: The jurentile court counselor is responsible for obtaining the pertinent social history data, sotting up a court hearing if necessary, and providing for an appropriate after-care plan. Juvenile court counselors typically saw the children assigned to them on a once-z-week basis. Most children remained under the supervision of their juvenile court counselor after being released from detention.

\section{PROCEDURE}

\section{Subjects}

The subjects were all males who had been admitted to the Boys III unit of the Donald E. Iong Home in Portland, Oregon. All subjects ranged from 14 to 17 years of age. The subjects all lived together in the same detention unit and were all treated the same except as required by the experimental design. Subjects involved came from all levels of socioeconomic status and were detained on charges that ranged all the way from protective custody and curfew through homocide. The subject population in the unit on any given day ranged anywhere from 15 to 24 children. The average length of stay per subject was 10 days.

\section{Sample Size}

The total number of subjects participating during the three month study period was 282. The two experimental groups, $\mathrm{E}_{1}$ and $\mathrm{E}_{2}$, contained 95 and 93 subjects respectively. The control group, $c_{1}$, contained a total of 94 subjects.

\section{Random Assignment}

In order to maintain equality of groups, all subjects were assigned to a group $\left(E_{1}, E_{2}, C_{2}\right)$ on the basis of a previously recorded 
random selection table according to their order of admittance into the detention unit. Subjects who were in a group requiring an individual groupworker counselor $\left(E_{1}, E_{2}\right)$ were assigned to one of the six staff members involved, on the same random basis (Table I). Both tables were determined by the throw of a die.

\section{TABLE I}

GROUPWORKER

\begin{tabular}{lllllll|} 
& 1 & 2 & 3 & 4 & 5 & 6 \\
\hline$E_{1}$ & $E_{2}$ & 17 & 18 & 15 & 16 & 17 \\
\cline { 2 - 7 } & 14 & 15 & 15 & 16 & 16 & 17 \\
\hline
\end{tabular}

Table I: Subject distribution among groupworkers for the two "counseling groups."

\section{Groups}

$E_{1}$ - Experimental Group. Approximately one-third of the subjects admitted to the Boys III unit during the three month study were randomly assigned to the Experimental Group $\left(E_{1}\right)$ referred to as "counseling group." In this group the subjects were randomly assigned to one of the six groupworkers. They were informed upon admission that the court was currently involved in a study to determine the effects of assigning a child a specific groupworker as a "detention counselor." It was explained that they would still have a jurenile court counselor who would be responsible for future planning in the case. Furthermore, they would have a detention counselor who was to help aid in their adjustment to detention and with any special problems they encountered within this group living situation. It was also explained that his detention counselor would be meeting with him formally a minimum of 
twice the first woek and at least once a week thereafter, and for the child to ask to speak with his detention counselor if ho had any questions or problems that arose. During this time, the child was also given the standard orientation given to all children admitted to detention. While they were detained the subjects in this group experienced the typical "group process" program that the detention home employs. $E_{2}$ - Social Interaction Group. This group served as a secondary experimental group $\left(\mathrm{E}_{2}\right)$. They were oriented in the same manner as the $\mathrm{E}_{1}$ group and were assigned a detention counselor. In this group, however, the detention counselor did not counsel them, he merely showed them some "individualized attention" by an occassional game of pingpong, cards, etc. The boys in this group were of the opinion that they were being treated the same as the boys in the $E_{1}$ group. As the other groups, they were given the standard orientation and were involved in the "group process" program to the same extent as the other children.

$$
c_{1} \text { - Control Group. A third group of children, comprising }
$$
approximately a third of all subjects, consisted of the control group $\left(c_{1}\right)$. This group received no "spocial" treatment of any kind. They were, of course, involved in the "group process" program as were all children in the detention facility. Upon admittance the subjects were given the standard detention orientation and informed to contact any of the groupwork staff if they had any particular problems. They were informed that a study was being done, but that it would in no way effect them.

\section{EXPERIMENTAL DESIGN}

To insure that the groupwork staff would have adequate knowledge 
of counseling techniques, they were given four hours of training prior to the study. The training was comparable to the instruction one would receive in terms of on-the-job orientation. The guide lines used in this training were from the standardized instruction manual for detention counseling drawn up by the Los Angeles County Jurenile Detention System (Ios Angeles County Juvenile Hall Operation Manual, 1968). The author had previously been employed by Los Angeles County, and had been trained in this technique. A detailed description of this training method is included in the Appendix I.

In order to analyze the treatment groups $E_{1}, E_{2}$, and $C_{1}$ in terms of length of stay, the following "diagnostic" groups were devised: "Diagnostic" Group A - Those subjects who were detained less than 7 days; "Diagnostic" Group B - Those subjects who were detained from 7 to 14 days; "Diagnostic" Group C - Those subjects who were detained more than 14 days. The term "diagnostic" should be viewed solely as a catagorical classification indicating time spent in detention and should not be interpreted in any other manner. Subject distribution across "treatment" and "diagnostic" groups is shown in Table II.

\section{TABLE II}

\begin{tabular}{|c|c|c|c|c|}
\hline $\begin{array}{l}\text { "Diagnostic" } \\
\text { Groups }\end{array}$ & $\frac{E_{1}}{\text { Treatment }}$ & $\begin{array}{c}\mathrm{E}_{2} \\
\text { Social } \\
\text { Interaction }\end{array}$ & $\stackrel{\mathrm{C}_{1}}{\text { Control }}$ & Total \\
\hline (A) $1-6$ days & 62 & 59 & 65 & 186 \\
\hline (B) $7-14$ days & 15 & 21 & 13 & 49 \\
\hline $\begin{array}{c}\text { (c) } 15 \text { days or } \\
\text { more }\end{array}$ & 18 & 13 & 16 & 47 \\
\hline Total & 95 & 93 & 94 & 282 \\
\hline
\end{tabular}

Table II: Distribution of S's among the "treatment" and "diagnostic" groups. 
Testing of the hypothesis was done in reference to whether a child received "detention counseling" $\left(\mathrm{E}_{1}\right)$, received "individualized attention" $\left(E_{2}\right)$, or received neither of these $\left(C_{1}\right)$ in respect to how long the child had been in detention. Evaluation of this problem was approached in three ways: Observations of subject's behavior (Behavior Activity Inventory); staff attitudes regarding subject outcome (Rating Scale); and, a subject questionaire (Opinion Sheet). These three instruments were developed to determine the amount of change, if any, in respect to the control of behavior of children detained in a detentional facility.

Data obtained from the measurement devices were subjected to a $3 \times 3$ Analysis of Variance Design, with unequal groups (Edwards, 1972). This held true for all items on each of the three instruments with these exceptions: A $2 \times 3$ Analysis of Variance and two yes/no response items. Significant "f" Values were analyzed using Duncan's Multiple Range Test (Edwards, 1972; Kramer, 1956).

\section{INSTRUMENTS}

There were a total of three measurement devices utilized in an attempt to determine the amount, if any, of a behavioral or attitudinal change. A description of these three instruments are as follows.

Instrument \#1 - The Behavior Activity Inventory (B.A.I.)

The B.A.I. was adapted from the Location Activity Inventory (L.A.I.) that was developed by Hunter, Schooler, and Spohn (1962) and further improved upon by Fairweather (1964). The I.A.I. was devised as "a method for the objective and systematic observation and recording of detailed information concerning the daily personal and social behavior of 
patients in a mental ward." (Fairweather, 1964) Basically, the I.A.I. was a highly sensitive checklist that allowed for obtaining a ten second sample of patient's behavior each day by trained observers. The reliability of such an instrument in the study of a confined patient population had previously been confirmed. Due to the uniqueness of this jurenile population, however, and the study of different types of behavior, it was necessary to modify the L.A.I.. The L.A.I. as utilized by Fairweather (1964) in his study of chronically hospitalized mental patients contained 12 categories organized into 3 primary areas. The 3 areas were: 1) Location, 2) Physical Activity 3) Social Activity. The Physical Activity categories were geared toward the study of chronic mental patients and were, therefore, not utilized. The Location and Social Activity areas were pertinent to our population and were utilized. Two additional areas were added and they were: 1) Freedom of Movement 2) Negative Behavior.

The "Location" category of the B.A.I. was such to provide an accurate picture of which areas of the detention unit a particular child frequented most often in respect to "treatment" group and length of stay. The various areas of the unit were grouped into throe primary areas according to the amount of social activities that took place in each. These were determined by having staff rate each room on a scale of $I$ to 3, and grouping areas of agreement. Area 1, that of the least social activity, included the laundry room, clothing room, staff office, kitchen and dining room (observations were not made during mealtime). Area 2 included the north hallway, east and west bedrooms, dormitory, south hall and bathroom. Area 3, that of greatest social activity, included the classroom, craftroom, living room, and game room. In 
addition to recording the room frequented during the observation period, it was also noted as to whether or not a child entered or left during the time the observer was recording. This allowed the observers a check against observing a subject twice in one observation period.

The "Social Activity" category was such as to distinguish between five classes of social behavior, all of which were assigned differential scores along a continuous scale of social activity. The lowest ordered subcategory was that of "Parasocial Activities" (1). This consisted of socially oriented types of behavior that occurred without the direct or irmediate presence of another individual. Examples of such activities are reading, writing, presence in a non-social group, doodling, watching television, or observing an activity without active involvement. "Parasocial Behavior" (2) was the next subcategory and consisted of behavior directed towards another group or individual without further involvement with that group or person. Brfef interactions of this nature consisted of greeting someone, gesturing to another, or somehow briefly acknowledging the presence of another. The next ordered subcategory was a "Two-Person Interaction" (3). This consisted of a child being actively involved in a conversation, game, etc., with another individual. A "Three-Person Group" (4) made up the fourth subcategory and involved a child being actively involved with two other people. The final subcategory was termed a "Social Group" (5). A score in this area indicated that the child being observed wes actively participating in a group comprising more than three people.

The third major category, "Freedom of Movement", was devisod to determine the degree of co-operation the child was oxhibiting in the detention unit. As in many detention facilities, one of the staff's 
primary methods of controlling behavior was to restrict the child's mobilfty within the unit. In an attempt to identify this class of behavior, five subcategories were utilized, and they too were assigned differential scores along a continuous scale. The five subcategories were: "Unrestricted" (1); "Disciplinary Restriction" (2); "Room Restriction" (3); "Locked in Room" (4); and "Isolation" (5). In the "Dnrestricted" class a child was free to roam the unit at will, with the excoption of certain areas such as the groupworker's office. This degree of mob1lity indicated that the child had been co-operating with the staff and was, therefore, assigned the lowest (most desirable) scaled score. "Disciplinary Restriction" indicated that the child had committed some type of minor rule infraction and because of that, had been restricted to the living room area. If a child was on "Room Restriction" this meant that he had committed several rule infractions, or had been inrolved in a more serious incident and had been sent to his room for a period of time. In these cases the door to his room was not locked. The next most serious subcategory was "Locked in Room". This occurred when a child had been sent to his room (Room Restriction) for discipllnary purposes and would not stay in his room or had caused further problems. The final and most serious disciplinary problem involved "Isolation". Two rooms in the unit were specially designed security rooms and were utilized when a child was unmanagable in the group or had been involved in a very serious acting out, such as attempting to "break outn, attacking a groupworker, etc. The observers were not famillar enough to know which children were on "Disciplinary" or "Room Restriction", so it was necessary to check with the staff as to which children foll into these catogories. The other examples were clear onough simply 
by observation.

The fourth and final major category was laboled Nogative Behavior". This was made up of nine subcategorfes, each viewed as a progressively more negative type of behavior. The first being, "VerbalNon-Social" (I), and involved a child complaining or 'muttering' to himself about something he did not like. The second, "Arguing" (2), indicated a child was actively involved in a verbal disagreement with another individual. The next subcategory was that of "Hostility" (3). Here a child needed to be engaged in a vorbal disagreement and exhibiting some form of hostility, such a cursing, a loud or angry tone of voice, etc. Subcategory number four of "Negative Behavior" was termed "Gesturing" (4). "Gesturing" involved a negative physical motion directed at another person. Examples would be 'flipping the bird', raising a clenched fist and so forth. Following this was "Disobeying Unit Rulos" (5). The sixth subcategory, "Refusing to Co-operate with Others" (6), included verbal refusals to do whatever was being asked of him. The next area, "Interfering with Other s" (7), amounted to a physical type of interference, such as pushing someone out of the way, tipping over someone's checker game, otc. The final two categories, "Destroying Property" (8) and "Physical Confrontation" (9), are self descriptive. A miscellaneous category termed "Critical Incidents" was added for observers to write in an incident otherwise uncovered. Of more than 1,500 individual observations, only four such incidents were recorded.

Observere: In selecting observers for data collection on the B.A.I., it was decided to use individuals who were not directly involrod in the project, but who were familiar with the operation of the detention home. Student lides were best suited for this purpose. Throe 
male students, who were from various colloges in the community and wero currontly involved in a field placement in other units at the detention home, were selected. The students might also have the added advantage of being less of an authority figure, closer in age, and less threatening to the children. The students wore aldes in the other detention units and were, therefore, unfamiliar with the project and had no knowledgo of which group any particular child was in. The students had been present for over three months and were quite famillar with the procedure and rules governing the detention units.

Prior to the actual data collection each of the three observers were given two hours of instruction on how to use the instrument and ten practice observations (See Appendix II). Then the observers all recorded observations on 25 subjects on 4 seperate occasions prior to the otudy. The 300 observations of the observers were then compared for the degree of reliability. The results of this reliability check are summarized in Table III; degree of inter-observer correspondence is expressed as percentage of agreement for each of the B.A.I. categories. The average rater agreement was above $89 \%$ in all cases, indicating that in the hand of trained observers, the B.A.I. is a reliable rating instrument.

The reliability was chocked again in the same manner half way through the study to insure that continued experience with the instrument does not have a negative effect on the inter-rater reliability. The results of the half way chock indicated a slightly higher over-all average rater agreement which would oupport the fact that continued experience with the instrument does not have a negative offect upon the reliability of the B.A.I. The rosults of this check are summarized in Table N. 
\% of Inter-Rater Agreement

(First Check)

\begin{tabular}{|c|c|c|c|c|c|c|c|c|c|c|}
\hline $\begin{array}{l}\text { Observation } \\
\text { Period }\end{array}$ & $\mathrm{N}$ & Location & $\begin{array}{l}\text { Freedom of } \\
\text { Movement }\end{array}$ & $\begin{array}{l}\text { Funct. } \\
\text { Non-Soc. }\end{array}$ & $\begin{array}{l}\text { P.S. } \\
\text { Act. }\end{array}$ & $\begin{array}{l}\text { P.S. } \\
\text { Behar. }\end{array}$ & $\begin{array}{l}\text { Neg. } \\
\text { Verb. } \\
\text { Behav. }\end{array}$ & $\begin{array}{l}\text { Neg. } \\
\text { Behav. }\end{array}$ & $\begin{array}{l}\text { Soc. } \\
\text { Act. }\end{array}$ & $\begin{array}{l}\text { Crit. } \\
\text { Inc. }\end{array}$ \\
\hline I* & 25 & 98.67 & 96.00 & 97.33 & 89.33 & 96.00 & 96.00 & 98.67 & 90.67 & 100.00 \\
\hline $2 *$ & 25 & 100.00 & 100.00 & 98.67 & 85.33 & 97.33 & 94.67 & 100.00 & 92.00 & 100.00 \\
\hline $3 *$ & 25 & 95.33 & 98.67 & 100.00 & 88.00 & 94.67 & 96.00 & 100.00 & 93.33 & 100.00 \\
\hline $4 *$ & 25 & 98.67 & 100.00 & 98.67 & 92.00 & 100.00 & 97.33 & 100.00 & 93.33 & 100.00 \\
\hline Totalg** & 100 & 98.17 & 98.67 & 98.67 & 88.67 & 97.00 & 96.00 & 99.67 & 92.33 & 100.00 \\
\hline
\end{tabular}

* - Average of $\$$ of Agreement of three raters

* - Overall (100 observationg) \& of Rater Agreement

TABLE III: Average $\not$ of Inter-Rater Reliability Prior to Study.

Average $\%$ of Agreement between Raters 1 and 2; 1 and 3; and 2 and 3 over each of the four observation periods. Totals indicates the Average $\%$ of Agreement over all Observations ( 100 ). 
\% of Inter-Rater Agroement

(Half Way Check)

\begin{tabular}{|c|c|c|c|c|c|c|c|c|c|c|}
\hline $\begin{array}{c}\text { Observatio } \\
\text { Period } \\
\end{array}$ & $\mathrm{N}$ & Location & $\begin{array}{c}\text { Froodom of } \\
\text { Movement }\end{array}$ & $\begin{array}{c}\text { Funct. } \\
\text { Non-Soc. }\end{array}$ & $\begin{array}{l}\text { P.S. } \\
\text { Act. }\end{array}$ & $\begin{array}{l}\text { P.S. } \\
\text { Behs. }\end{array}$ & $\begin{array}{c}\text { Neg. } \\
\text { Verb. } \\
\text { Behar. }\end{array}$ & $\begin{array}{l}\text { Neg. } \\
\text { Behav. }\end{array}$ & $\begin{array}{l}\text { Soc. } \\
\text { Act. }\end{array}$ & $\begin{array}{l}\text { Crit. } \\
\text { Inc. }\end{array}$ \\
\hline $1 *$ & 25 & 98.00 & 98.66 & 98.66 & 92.67 & 96.00 & 96.67 & 96.67 & 92.67 & 100.00 \\
\hline $2 *$ & 25 & 100.00 & 98.00 & 94.67 & 92.67 & 95.33 & 96.00 & 99.33 & 95.33 & 100.00 \\
\hline $3 *$ & 25 & 96.67 & 99.33 & 98.67 & 92.00 & 96.67 & 99.33 & 99.33 & 98.67 & 100.00 \\
\hline $4 *$ & 25 & 100.00 & 100.00 & 97.33 & 87.33 & 96.00 & 98.67 & 100.00 & 94.67 & 100.00 \\
\hline Total * & 100 & 98.67 & 99.00 & 97.32 & 91.18 & 96.00 & 97.67 & 98.83 & 95.34 & 100.00 \\
\hline
\end{tabular}

TABIE IV: Average $\$$ of Inter-Rater Reliability Midway through the Profect. 
Daily B.A.I. observations were recorded during the "free time" periods on both the $7,00 \mathrm{a} . \mathrm{m}$. to $3,00 \mathrm{p} \cdot \mathrm{m}$. shtft and the $3,00 \mathrm{p} . \mathrm{m}$. to 11:00 p.m. shift. Observations were alternated from one shift to the next, each day, so as to rule out any bias that might be introduced by the time of day or the staff working any particular shift. Upon entering a room the observers first task was to reoord the name of each individual present. only after all names were recorded would the rater observe and record, in turn, the behavior of each. Observations of a particular subject were to be of 10 seconds duration and each subject was rated only once during any particular rating period. The behavior was recorded by merking the appropriate categories on the B.A.I. scoring sheet used each day (Sample in Appondix II).

Observers were instructed to begin each day from alternating end of the detention unft and to maintain a passive role with the children. "Passive" was defined to observers as answering questions and responding appropriately, but to avoid initiating or prolonging contacts with the subjects.

Periodically, every two to three weeks, the groupwork staff would briefly explain the role of the observers. In general, the children showed very little concern regarding the observers after the first two weeks of the study. All through the first two weeks there was a fairly high degree of curlosity, however, this did not appear to have serious consequences.

The only problem encountered in utilizing this perticular method of data collection, was the initial unfamiliarity of the observera with the children. Until the rators became familiar enough with the children to remember their names, the raters had to occasionally check with the 
groupworker for identification prior to entering or immediately after leaving a room. After three woeks, the raters wero able to recognize the majority of individuals and then only had to concern themselves with learning the identity of a now admittee. Now admittees were few enough that this did not present any particular problems.

\section{Scoring of the B.A.I.: In order to compare treatments, it was} necessary to assign every individual a score on each of the four major B.A.I. categories. This was accomplished by a weighted scoring technique for which a mean score was computed. For example, the five Freedom of Movement categories were ordered such thet a score of 1 was assigned to "Unrestricted", 2 to "Disciplinary Restriction", and so on, up to a score of 5 for "Isolation." Thus, each child received a single overall Freedom of Movement score by adding the number of times he was marked per subcategory, multiplying the sum of the subcategories score by their assigned weight, and suming the products of all five subcategories. This score was then divided by the number of observations per subject, resulting in a mean score. A mean score of 1.0 in this category would indicate that a child's freedom of movement was never restricted during an observation period. A mean score of 5.0 would indicate that the child was isolated during each observation period. Therefore, the higher the mean score, the more the child's freedom of movement was restricted and he would be considered more of a management problem in detention.

Similar procedures were employed with the remaining threo categories. The five Social Activity subcategories were ordered and weighted on the basis of the dogree of social activity involved. These ranged from "Parasocial Activities" (1) to "Social Group" (5). The higher the 
mean score, the higher the degree of social involvement with others. The three Location subcategories were ordered according to the amount of activity in each area. Area 1, that having been frequented the most, was assigned a score of 1. Area 2, a score of 2. Area 3, a score of 3. "Therefore, the higher the mean score, the more the subfect frequented areas that involved higher degrees of social activities. The final category, Negative Behavior, contained nine subcategories. They were ordered on the following basis: "Verbal-Non Social" (I), "Arguing" (2), and so on, up to "Destroying Property" (8), and "Physical Confrontation" (9). The higher the mean score, the more negative was the behavior exhibited. After collection of the date, it was determined that nine levels were excessive and the original nine subcategories were reduced to three. For purposes of statistical analysis levels I through 3 were assigned a score of 1, levels 4 through 6 a score of 2 , and levels 7 through 9 a score of 3. This allows for a subject to obtain a score of 0 to 3 on any particular observation. A zero score was necessary as the original nine subcategories were not inclusive of all possible behavior. A mean score of 3 would indicate very negative behavior.

In accordance with the above procedures, the original group of 30 separate B.A.I. listings were condensed to four average scores for each chlld. They are: Location (1); Freedom of Hovement (2); Social Activity (3); and Negative Behavior (4). Of the 282 subjects, 55 were lost due to one of two problems. First, the subjects who were admitted late at night and released several hours later, or early the next day, before an observation could be obtained. Secondly, the subjects who were detained only one or two days and were unavailable during the time observations were made. The 227 subjects that B.A.I. observations were made upon are 
shown in Table 5.

\section{TABLE V}

"Diagnostic" Groups

(A) 1-6 days

(B) 7-14 days

(c) 15 or more

days

Total
$\stackrel{\mathrm{E}_{1}}{\text { Treatment }}$

47

13

17
Social Interaction

44

20

12
$\stackrel{\mathrm{C}_{7}}{\text { Control Total }}$

47

12

15

74
138

45

44

Table V: Number of subjects involved in B.A.I. observations in each of the three "diagnostic" groups for the three treatment groups.

Expectations: The expected results for this portion of the study were that those children in the $E_{1}$ group would receive significantly higher mean scores in the Location and Social Activity categories than the children in the $\mathrm{C}_{1}$ or $\mathrm{E}_{2}$ groups. It was also expected that the $\mathrm{F}_{1}$ group would exhibit significantly lower scores in the Negative Bohavior and Freedom of Movement categories. No significant differences were expected in any category between the $C_{1}$ and $E_{2}$ groups.

Iikewise, the children in "diagnostic" group C (detained more than 2 weeks) were expected to receive significantly higher mean scores in the Location and Social Activity categories and lower mean scores in the Negative Behavior and Freedom of Movement than either groups A or B. Group B (7-14 dajs) was also expected to be significantly different from Group A in a similar manner.

\section{Instrument \#II - Attitudinal Rating Scale}

Prior research indicates that a great deal of information would 
be lost without a method of tapping the groupwork staff's knowledge of the individual child's behavior and attitude while in detention (Hardy, 1973). The groupwork staff were all college graduates, had received a great deal of on-the-job training, and were experienced professional child care workers. In an attempt to utilize this resource, the Attitudinal Rating Scale was developed.

The first step taken to develop such an instrument, was to request each of the seven groupworkers involved to submit a list of areas that they felt were important indicators of adjustment to detention life. In doing so, they were also asked to objectively define each area they listed. Once the seven lists were obtained, several meetings were held with the staff involved in an attempt to obtain agreement on the critical areas and the definition of each.

The original 20-odd areas of concern were reduced to seven major areas. Many of the original areas overlapped each other and the staff felt that the seven chosen, adequately represented the original ideas. The seven areas and definitions agreed upon by the staff were:

Behavior: Does not act out frustrations; follows unit routine; does not get involved in subversive activities.

Attitude: Shows positive feelings towards detention and others; does not act in a 'cocky' manner; demonstrates flex1bility in dealing with others.

Cooperation: Does what he is asked to do; demonstrates a willingness to help others; accopts discipline in a realistic manner.

Initiative: Does unit work without being asked; demonstrates a great deal of self-reliance; does not need to be prodded to participate.

Relationship with Staff: Appears comfortable interacting with staff; interacts honestly and openly; does not rebel against authority. 
Relationship with Poers: Respected by others; has a great deal of friends; does not get into fights or arguments.

Adherence to Ruless Requires a minimum of supervision; follows rules willingly; never requires discipline.

Once consensus was obtained on the areas most typifying a child's adjustment to dotention life, it was necessary to devise an appropriate method of rating these areas. A five point rating scale was utilized for this purpose. Definitions of the fire scales are as follows:

Rating of 1: Never descriptive of the child.
Rating of 2: Rarely descriptive of the child.
Rating of 3: Sometimes descriptive of the child.
Rating of 4: Mostly descriptive of the child.
Rating of 5: Always descriptive of the child.

The procedure for administering the rating was such that both groupworkers on duty, at the time a child was admitted, were to rate the child on all seven categories. Then at the end of one week, the same two raters were to again rate the child. Finally, the child ras rated again by both groupworkers upon being released from detention. If a child was released before the end on one week, he was rated only upon admiszion and release.

The child was rated by two staff members so that an average ratIng could be obtained which would rule out the biases of any particular staff member. Occasionally, however, children wero admitted during the night when only one groupworker was on duty. In these ceses, only one initial rating was obtained. This situation arose with less than $30 \%$ of the new admissions. When this did occur, the two groupworkers relieving the night man were then responsible for the ratings obtained at one week and upon release. This was done due to the fact that the day staff had much more contact with the children and were therefore in a better position to rate the child. 
Children were seldom ever released on the night shift (fewer than a dozen cases), so the problem of a single rating upon release was of little consequence.

The only other problem encountered with this method occurred when one of the staff involved in the previous ratings was on his day off when the child was released. Staff's days-off were staggered so that only one of the original raters would be off duty on any particular day. When this did occur, the rating of the original rater, on duty, was averaged with the rating of his present co-worker. This occurred with fewer than $20 \%$ of the release ratings.

Once the data had been collected, each child received an averaged rating on a five point scale for each of the seven major categories. Children in detention more than seven days received three averaged scores. The second rating was not included in the data analysis due to the fact "diagnostic" group $C$ was the only sample in which an adequate number of ratings could be obtained and this did not allow for acceptable comparisons.

As in the B.A.I., there were three treatment groups $\left(E_{1}, E_{2}, C_{1}\right)$, and three "diagnostic" groups $(A, B, C)$. Again some of the original 282 subjects were lost. This was due primarily to the fact that occasionally children would leave detention of a temporary "home visit", or "trial foster home visit" basis and would be released without returning to the institution. There were a total of 269 subjects involved in this measurement and their assignments to groups are illustrated in Table VI.

At a later point in the study, upon reviewing the seven major cat gories, it was decided that they all appeared to have a common dengminator; reaction to authority. Because of this similiarity it was felt 
that the seven categories could be combined together to form a more general category termed "Relating to Authority". This was done for the analysis of the data. Therefore, the averaged scoro for each child on each of the seven orfginal categories were lumped together to produce an overall average score per child. This averaged score was then treated as the staff's evaluation of how that particular child was rated in reference to his adjustment to detention life. The lower the score, the more the subject was seen $a 8$ having problems relating to authority. Expectations: It was expected that the children in the $E_{l}$ group would receive a significantly higher rating than the children in the $C_{1}$ and $E_{2}$ groups. Also, significant differences wero not expected between the $C_{1}$ and $E_{2}$ groups. A significantly higher rating was predicted for the $C$ group as compared to the $A$ and B groups. Group B was also expected to receive a significantly higher rating than Group $A$.

TABLE VI

\begin{tabular}{|c|c|c|c|c|c|}
\hline \multicolumn{2}{|c|}{$\begin{array}{l}\text { "Diagnostic" } \\
\text { Groups }\end{array}$} & $\underset{\text { Treatment }}{\mathrm{E}_{1}}$ & $\begin{array}{c}\mathrm{E}_{2} \\
\text { Social } \\
\text { Interaction }\end{array}$ & ${ }_{\text {Control }}^{c_{1}}$ & Total \\
\hline (A) & $1-6$ dey 8 & 60 & 58 & 64 & 182 \\
\hline (B) & $7-14$ days & 13 & 19 & 12 & 44 \\
\hline (c) & $\begin{array}{l}15 \text { or more } \\
\text { day } 8\end{array}$ & 17 & 12 & 14 & 43 \\
\hline & Total & 90 & 89 & 90 & 269 \\
\hline
\end{tabular}

Table VI: Number of subjects involved in the attitudinal rating scale in each of the three "diagnostic" groups for the three treatment groups. 
Instrument \#3 - Opinion Sheet

In attempting to obtain feedback from the subjects involved, an Opinion Questionnaire was derised. Upon release from detention each child was asked to fill out the following questionnaires

\section{Opinion Sheet}

When admitted to Boys 3 you were informed that you would be placed in one of two groupsi 1) Group Process or 2) Group Process, plus individual detention counseling. Now that you have had a chance to observe both groups and are leaving detention we would like to get your opinion on which group, if any, appeared to be the most helpful. Please answer the following questionnaire.

1) Did you receive individual detention counseling? Yes No

2) Rate the group you were in: Never helpful Rarely helpful Sometimes helpful Usually helpful Always helpful

3) Fate the group you were not in: Never helpful

Rarely helpful Sometimes helpful

4) Rate your detention eounselor: Never helpful Rarely helpful Usually helpful Somotimes helpful Always helpful

5) If given your choice, would you prefer an individual detention counselor? Yes No

Filling out the questionnaire was the last thing the child did before he was released from the unit. The children were assured that their responses would be confidential and would in no way affect their reloase or themselves, should they return at a later dato. The questionnaires wer coded only as to whieh treatment group and which "diagnostic" group 
the child was in. The questionnatres were coded in such a manner, after the child left the unit and out of sight of the remaining children, to avoid any suspioion that the groupworker might be marking the child's name on the paper.

Question number one was included as a chock to determine the effectiveness of the subject's orientation to detention, and also whether or not the "counseling" techniques were viewed appropriately. Questions two through five were included as methods of obtaining a subjective evaluation of the project as seen through the eyes of the children involved. Questions two, three and four rero assigned a scale value of 1 to 5. "Never Helpful" recelving a scale value of one and "Always Helpful" recelving a value of five.

Like the B.A.I. instrument and the Attitudinal Rating Scale, there were throe treatment groups $\left(E_{1}, E_{2}\right.$, and $\left.C_{1}\right)$ and three "diagnostic" groups $(A, B$, and $C)$. A total of 36 subjects were lost due to reasons assigned to previous loss of subjects. The breakdown of subjects in each group is shown in Table VII.

\section{TABLE VII}

\begin{tabular}{cccc|c}
$\begin{array}{c}\text { Miagnostic } \\
\text { Groups }\end{array}$ & $\begin{array}{c}E_{1} \\
\text { Treatment }\end{array}$ & $\begin{array}{c}\mathbf{E}_{2} \\
\text { Interaction }\end{array}$ & $\begin{array}{c}C_{1} \\
\text { Control }\end{array}$ & Total \\
(A) $1-6$ days & 61 & 56 & 63 & 180 \\
(B) $7-14$ deys & 12 & 19 & 12 & 43 \\
(C) 15 or more & 16 & 12 & 15 & 43 \\
\cline { 2 - 3 } & 89 & 87 & 90 & 246
\end{tabular}

Table VII: Number of subjects involved in filling out the Opinion Sheet Questionnaire in each of the three "diagnostio" groups for the three treatment groups. 
Expectations: In regard to question number one, it was expected that all children involved would understand which group they had been in.

Treatment group $B_{1}$ was prodicted to rate thoir group significantly higher than either $B_{2}$ or $C_{1}$. Significant differences were not expected between group $E_{2}$ and $C_{1}$. Furthermore, statistically significant higher ratings wero expected between "diagnostic" groups $C$ and $B$, and between group B and group A. In other words, the longor a child was detained and exposed to individualized detention counseling, the higher the expected rating on question number two.

Regarding question three, it was expected that those believing they were recolving detention counseling (treatment groups $E_{1}$ and $E_{2}$ ) would rate the non-counseling group significantly lower than treatment group $C_{1}$ would rate the "counseling" group $\left(E_{1}\right.$ and $\left.E_{2}\right)$. It was folt that feelings of group pride would increase with length of stay, but not significantly.

Question four applied only to treatment group $E_{1}$ and $E_{2}$. It was expocted that the $E_{1}$ group would rate their "counselor" significantly highor than group $\mathrm{E}_{2}$, and that this difference would increase significantly with increased length of stay.

The final prediction, regarding item fire, was that all groups would prefer an individual detention counselor, if giren a choice. 
RESULTS

Behavior Activity Inventory (B.A.I.)

As indicated previously, there were four primary areas of interest Involved in the Behavior Activity Inventory instrument: Location, Social Activity, Freedom of Movement and Negative Behavior.

Iocation: Prior to the full scale data analysis of subjects, a computation of the percentage of subjects in each of the three areas was made. Those percentages are as follows: Area 3 (classroom, craftroom, living room, and game room) contained $72 \%$ of all subjects; Area 2 (bedrooms, bathroom, and hallway) contained 21\% of all subjects; Area 1 (utility rooms, office, kitchen, and dining rooms) contained $7 \%$ of all subjects. Due to the fact that these figures agree with the original expectations when devising the location areas, and that there were no unusual variations from these percentages present among any of the treatment or "diagnostic" groups, a further evaluation of location scores was deemed unnecessary.

Social Activity: This category was included to determine the level of social activity a subject was involved in while in detention. The five levels of social activity were assigned differential scores ( 1 through 5) along a continuous seale. Starting with the lowest ordered subcategory (1) the five levels are as follows: Parasocial Activities, Parasocial Behavior, Two-Person Interaction, Three-Person Group, and Social Group. Therefore, subjects receiving a high score (5) would be considered to be more socially involved. 
The scores for each subject were tallied and divided by the number of observations obtained, resulting in a mean score. The mean scores of subjects in each of the treatment and "diagnostic" groups were then tallied and divided by the number of subjects per group. The resulting mean scores are shown in Table VIII and illustrated in Figure 1. The $3 \times 3$ ANOVA data is depicted in Table IX. Table X indicates Multiple Range Test results.

The data analysis indicates that there was a significant difference at the .05 level among the "diagnostic" groups. There were not, however, any significant differences among the treatment groups, nor any interaction effects.

Freedom of Movement: This category was included as an indicator of the degree of co-operation a child exhibited while in detention. This category, too, had five separate levels that were assigned differential scores ( 1 through 5) along a continuous scale. Beginning with the lowest ordered level (I) the five sub-categories were: Unrestricted, Disciplinary Restriction, Room Restriction, Iocked Room, and Isolation. The lower the score the more the child was co-operating with the rules. As with the social activity scores, each subject received a mean score and then each treatment and "diagnostic" group received a mean score. Results of this are indicated in Table XI and 1llustrated in Figure 2. Data analysis is shown in Table XII and Table XIII.

The statistical analysis reveals a significant difference among the "diagnostic" groups at the .05 level of significance. Significant differences were not found amng the treatment groups, nor among the interaction effects.

Negative Behavior: The final category of the Behavior Activity 
Inventory was designed to examine the more overt types of socially unacceptable behavior. It was possible for a subject to obtain a score of 0 to 3 on any particular observation. A mean score of three would indicate very negative behavior.

Each subject's scores were tallied and divided by the number of observation periods he was involved in, resulting in a mean score for each subject. These scores were then tallied for each of the treatment and "diagnostic" groups and mean scores obtained per group (Table XIV). An illustration of these scores is shown in Figure 2. Table XV shows the results of the statistical analysis, as does Table XVI.

Data analysis indicates significant differences at all levels. Significant differences (.05) were found for treatment groups, "diagnostic" groups, and the interaction effects.

TABLE VIII

\begin{tabular}{|c|c|c|c|c|}
\hline $\begin{array}{l}\text { "Diagnostic" } \\
\text { Groups }\end{array}$ & $\frac{E_{I}}{\text { Treatment }}$ & $\begin{array}{c}\mathrm{E}_{2} \\
\text { Social } \\
\text { Interaction }\end{array}$ & $\underset{\text { Control }}{C_{1}}$ & $\begin{array}{l}\text { Row } \\
\text { Means }\end{array}$ \\
\hline (A) 1-6 days & 1.45 & 1.05 & 1.46 & 1.32 \\
\hline (B) 7-14 days & 1.47 & 1.61 & 1.85 & 1.64 \\
\hline (c) $15 \underset{\text { days }}{15}$ or & 1.88 & 2.02 & 2.00 & 1.97 \\
\hline Column Means & 1.60 & 1.56 & 1.77 & 4.93 \\
\hline
\end{tabular}

Table VIII: Mean scores of each of the treatment and "diagnostic" groups on the Sjcial Activity scores obtained from the Behavior Activity Inventory. 
FIGURE 1
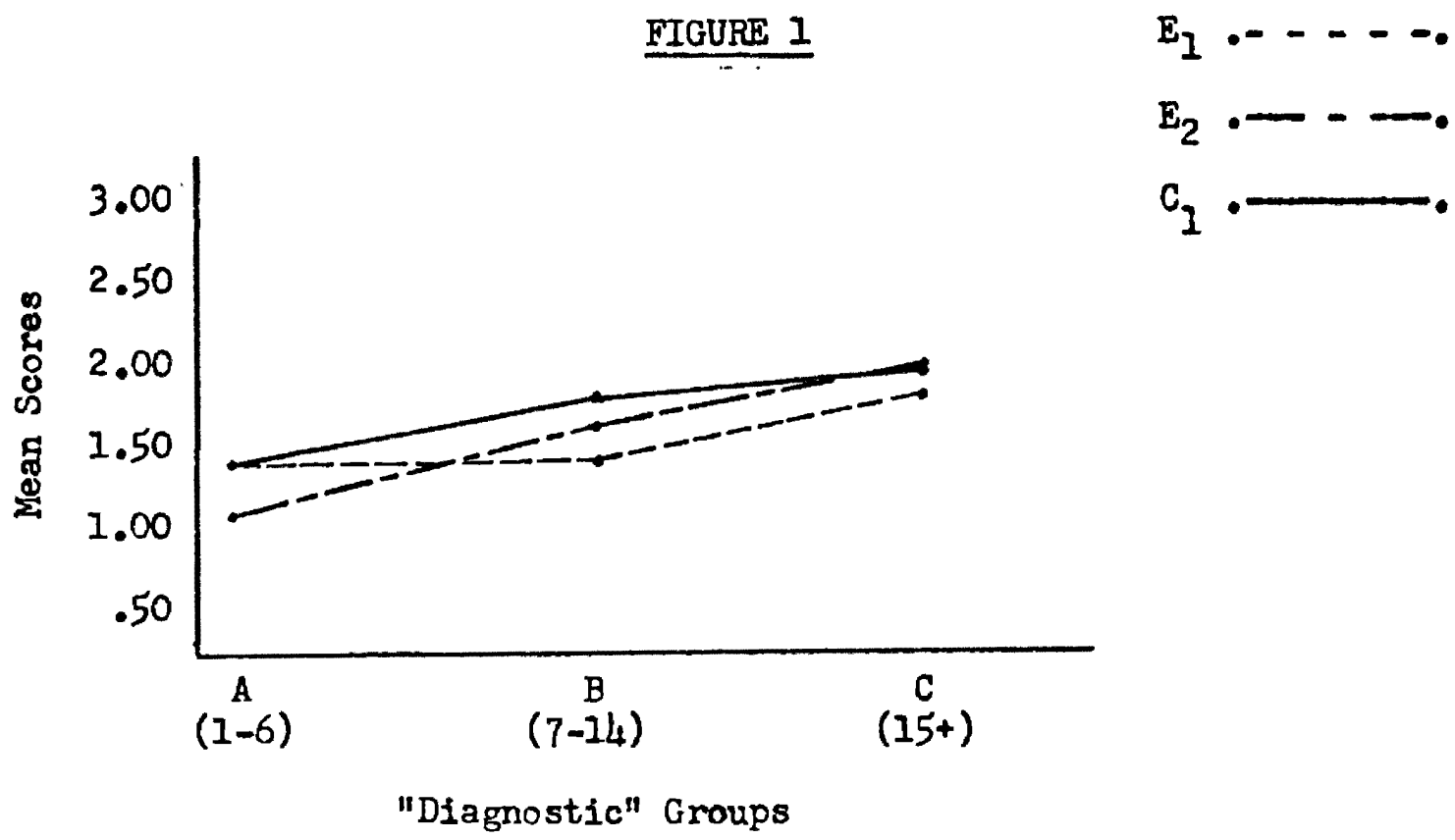

Figure 1: Illustration of mean scores of each of the treatment and "diagnostic" groups on the Social Activity Scores obtained from the Behavior Activity Inventory.

TABLE IX

\begin{tabular}{|c|c|c|c|c|}
\hline Source & $\leqslant s^{2}$ & $d f$ & $\begin{array}{c}\text { Mean } \\
\text { Square }\end{array}$ & $\mathbf{F}$ \\
\hline A ("Diagnosis") & .62 & 2 & .32 & $8.00 *$ \\
\hline B (Treatment) & .07 & 2 & .04 & 1.00 \\
\hline AxB ("Diagnosis" $x$ Treatment) & .12 & 4 & .03 & .75 \\
\hline Error & 8.72 & 218 & .04 & \\
\hline
\end{tabular}

$* 0.05$

Table IX: Results of the $3 \times 3$ ANOVA with unequal groups for the Social Activity Scores at the .05 level of significance. 
TABLE X: Results of a multiple range test with unequal groups applied to the differences between "diagnostic" means obtained from the Social Activity scores of the Behavior Activity Inventory. Tested at .05 level of significance.

Any two means not underscored by the same line are significantly different. Any two means underscored by the same line are not significantly different.

(1)

\begin{tabular}{|l|lll|}
\multicolumn{1}{c}{} & $\mathrm{A}(1-6)$ & $\mathrm{B}(7-14)$ & $\mathrm{C}(15+)$ \\
\hline$\overline{\mathrm{X}}$ & 1.32 & 1.64 & 1.94 \\
$\mathrm{n}$ & 138 & 45 & 44 \\
\hline
\end{tabular}

$A(1-6)$

$B(7-24)$

$c(15+)$
(2)

(3)

TABLE XI

$E_{2}$

"Diagnostic" Groups

(A) 1-6 days

(B) 7-I4 days

(C) 15 days or more

Column Means
$E_{1}$ Treatment

Social Interaction

$$
1.07
$$

1.31

1.01

1.16 


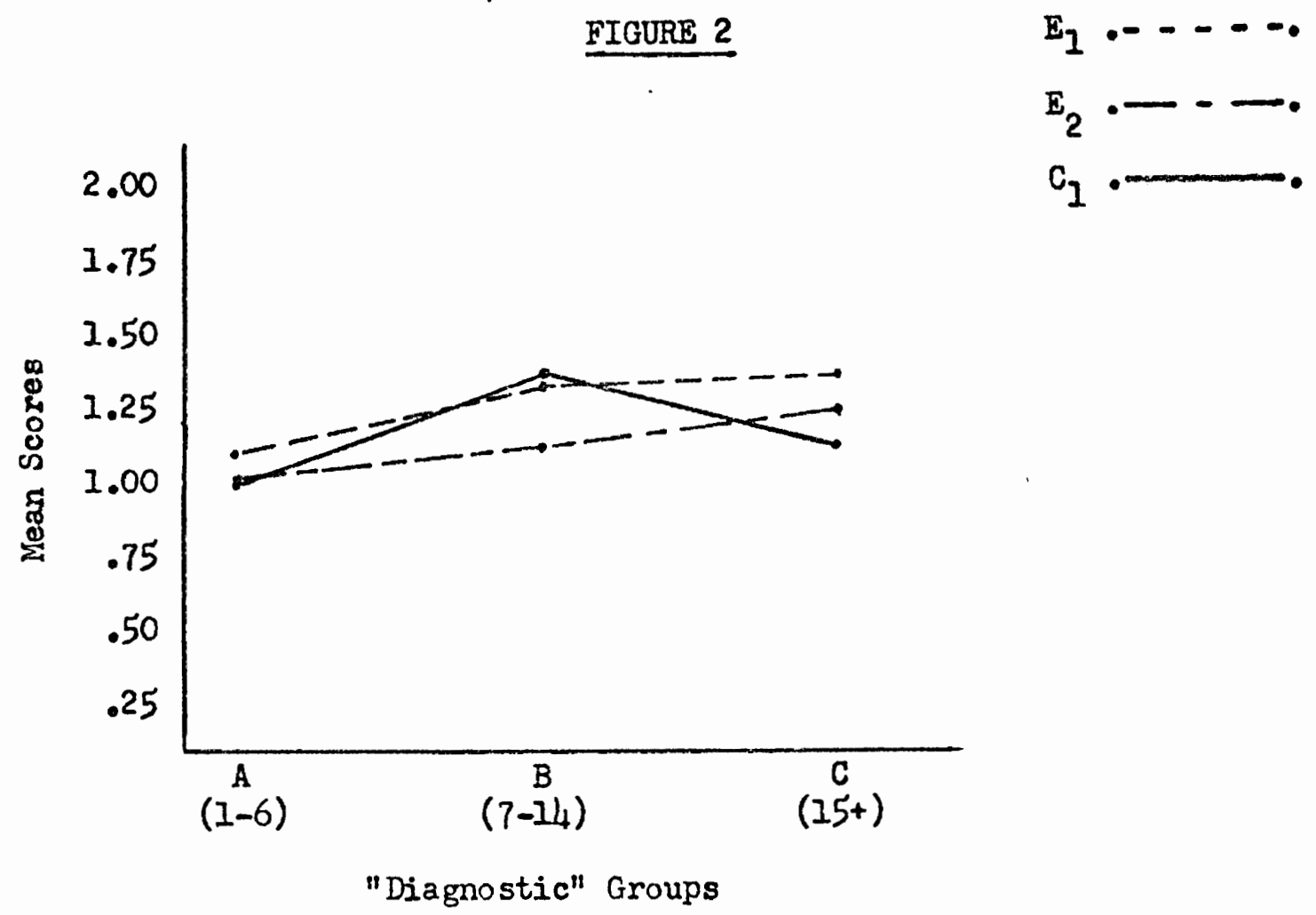

Figure 2: Illustration of the mean scores for each of the treatment and "diagnostic" groups on the Freedom of Movement scores obtained from the Behavior Activity Inventory.

TABLE XII

\begin{tabular}{|c|c|c|c|c|}
\hline Source & $\leqslant s^{2}$ & df & $\begin{array}{l}\text { Mean } \\
\text { Squase }\end{array}$ & $\mathrm{F}$ \\
\hline A ("Diagnosis") & .115 & 2 & .058 & $29.00 *$ \\
\hline$B$ (Treatment) & .018 & 2 & .009 & 2.25 \\
\hline AxB ("Diagnosis" $\times$ Treatment) & .032 & 4 & .008 & 2.00 \\
\hline Error & .87 & 218 & .004 & \\
\hline
\end{tabular}

Table XII: Results of the $3 \times 3$ ANOVA with unequal groups for the Freedom of Movement score of the Behavior Activity Inventory. Statistical significance tested at the .05 level. 
TABIE XIII: Results of a multiple range test with unequal groups applied to the differences between "diagnostic" means obtained from the Freedom of Movement scores of the Behavior Activity Inventory. Tested at .05 level of significance.

Any two means not underscored by the same line are significantly different. Any two means underscored by the same line are not significantly different.
(1)
(2)
(3)

\begin{tabular}{|l|lll|}
\hline \multicolumn{1}{|c}{} & $A(1-6)$ & $C(15+)$ & $B(7-14)$ \\
$\mathrm{X}$ & 1.02 & 1.25 & 1.27 \\
138 & 44 & 45 \\
\hline & $A(1-6)$ & $C(15+)$ & $B(7-14)$
\end{tabular}

TABIE XIV

\begin{tabular}{lccc|r}
$\begin{array}{c}\text { Diagnostic" } \\
\text { Groups }\end{array}$ & $\begin{array}{c}\text { E1 } \\
\text { Treatment }\end{array}$ & $\begin{array}{c}\text { Eocial } \\
\text { Interaction }\end{array}$ & $\begin{array}{c}\text { C1 } \\
\text { Control }\end{array}$ & $\begin{array}{c}\text { Row } \\
\text { Means }\end{array}$ \\
(A) $1-6$ days & .61 & .40 & 1.51 & .84 \\
(B) 7-14 days & .89 & 1.90 & 1.29 & 1.09 \\
(C) 15 days or & 1.56 & 1.33 & 1.56 & 1.48 \\
\cline { 2 - 5 } more & 1.02 & .94 & 1.45 & 3.41
\end{tabular}

Table XIV: Mean scores for each of the treatment and "diagnostic" groups on the Negative Behavior scores obtained from the Behavior Activity Inventory. 


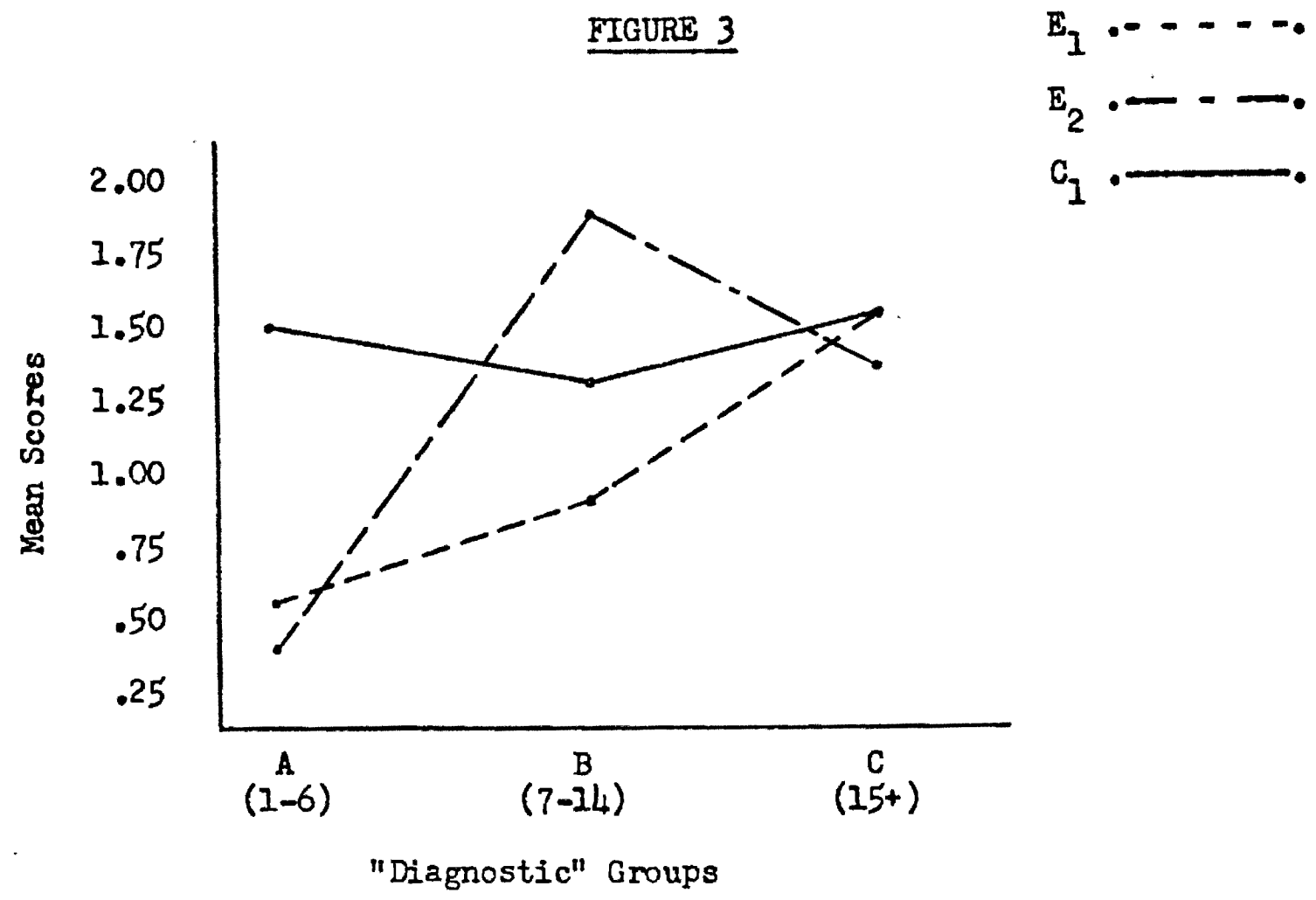

Figure 3: Illustration of the mean scores for each of the treatment and "diagnostic" groups on the Negative Behavior scores obtained from the Behavior Activity Inventory.

\section{TABLE XV}

\begin{tabular}{|c|c|c|c|c|}
\hline Source & $\left\{s^{2}\right.$ & $d f$ & $\begin{array}{c}\text { Mean } \\
\text { Square }\end{array}$ & $\mathbf{F}$ \\
\hline A ("Diagnosis") & .62 & 2 & .32 & $3.20 *$ \\
\hline B (Treatment) & .45 & 2 & .23 & $2.30 *$ \\
\hline AxB ("Diagnosis" $x$ Treatment) & .44 & 4 & .22 & 2.20 \\
\hline Error & 21.80 & 218 & .10 & \\
\hline
\end{tabular}

$* p<.05$

Table XV: Results of the $3 \times 3$ ANOVA with unequal groups for the Negative Behavior scores of the Behavior Activity Inventory tested at the .05 level of significance. 
TABLE XVI: Results of a multiple range test with unequal groups applied to the differences between the "diagnostic" means and botween treatment means obtained from the Negative Behavior scores of the Behavior Activity Inventory. Tested at .05 level of oigniflcance.

Any two means not underscored by the same line are significantly differont. Any two means underscored by the same line are not significantly different.

(1)

(2)

(3)

\begin{tabular}{|l|rrr|}
\multicolumn{1}{c}{} & $A(1-6)$ & $B(7-14)$ & $C(15+)$ \\
\hline $\bar{x}$ & .84 & 1.36 & 1.48 \\
$\mathrm{n}$ & 138 & 45 & 44 \\
\hline & $A(1-6)$ & $B(7-14)$ & $C(15+)$ \\
\hline
\end{tabular}

(1)

(2)

(3)

$\mathrm{E}_{1} \mathrm{E}_{2} \mathrm{C}_{1}$

\begin{tabular}{|r|rrr|}
\hline$\overline{\mathbf{x}}$ & 1.02 & 1.21 & 1.45 \\
$\mathrm{n}$ & 77 & 76 & 75 \\
\hline
\end{tabular}

$E_{1} \quad E_{2} \quad C_{1}$

Attitudinal Rating Scalo

The staff rated the subjects on a scale of 1 through 5 as previousiy described with a lower score being less desirable. Initial mean scoros were combined according to treatment and "diagnostic" groups and divided by the number of subjects per group, resulting in mean scores for each group (Table XVII). Results of the $3 \times 3$ ANOVA aro shown in Table XVIII. 
TABLE XVII

\begin{tabular}{|c|c|c|c|c|}
\hline $\begin{array}{l}\text { "Diagnostic" } \\
\text { Groups }\end{array}$ & ${ }_{\text {Treatment }}^{E_{1}}$ & $\begin{array}{c}\mathrm{E}_{2} \\
\text { Social } \\
\text { Interaction }\end{array}$ & $\begin{array}{c}c_{1} \\
\text { Control }\end{array}$ & $\begin{array}{l}\text { Row } \\
\text { Means }\end{array}$ \\
\hline (A) $1-6$ days & 3.01 & 2.95 & 3.16 & 3.04 \\
\hline (B) 7-14 days & 3.19 & 3.00 & 2.95 & 3.05 \\
\hline (c) 15 days or & 2.93 & 3.01 & 3.19 & 3.04 \\
\hline Colurn Means & 3.04 & 2.99 & 3.10 & 9.13 \\
\hline
\end{tabular}

Table XVII: Mean scores of Attitudinal Rating Scale obtained at time of admission.

\section{TABLE XVIII}

\begin{tabular}{|c|c|c|c|c|}
\hline Source & $\xi s^{2}$ & $\mathrm{~d} \mathbf{f}$ & $\begin{array}{l}\text { Mean } \\
\text { Square }\end{array}$ & $\mathbf{F}$ \\
\hline A ("Diagnosis") &.$\infty$ & 2 & 0 & 0 \\
\hline$B$ (Treatment) & .08 & 2 & .04 & .06 \\
\hline$A \times B$ ("Diagnosis" $\times$ Treatment) &.$\infty$ & 4 & 0 & 0 \\
\hline Error & 153.40 & 260 & .59 & \\
\hline
\end{tabular}

Table XVIII: Outcome of a $3 \times 3$ ANOVA with unequal groups on the mean 8cores obtained on the initial Attitudinal Rating Scale. Level of significance tested was .05 .

Significant levels of differences were not obtained in either the treatment or "diagnostic" groups, nor were there any significant interaction effects.

The rating scale obtained at the time of release was handled in a manner identical to that of the initial rating. Refer to Table XIX for the mean score data and to Table XX for sumnary of the significance 
analysis.

\section{TABLE XIX}

"Dlagnostic"
Groups

(A) 1-6 days

(B) 7-14 days

(0) 15 days or

Column Means
Treatment

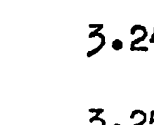

Social

Interaction $\underset{\text { Control Mow }}{\mathrm{C}_{2}}$

3.10

3.19.

2.89

3.07

3.09

3.10

\begin{tabular}{lll|l}
3.08 & 3.22 & 3.01 & 3.10 \\
\hline 3.19 & 3.17 & 2.90 & 9.26
\end{tabular}

Table XIX: Mean seores of Attitudinal Rating Scale obtained at time of release.

\section{TABLE XX}

\begin{tabular}{r|cccc}
\multicolumn{2}{c}{ Source } & \multicolumn{2}{c}{$\begin{array}{c}\text { Mean } \\
\text { Square }\end{array}$} & sf \\
\hline A ("Diagnosis") & .0002 & 2 & .001 & 0 \\
B (Treatment) & .300 & 2 & .150 & .17 \\
AxB ("Diagnosis" x Treatment) & 0 & 4 & 0 & 0 \\
& & & & .87
\end{tabular}

Table XXs Outcome of a $3 \times 3$ ANOVA with unequal groups on the mean scores obtained on the final Attitudinal Rating scale. Tested at the .05 level of significance.

Significant differences wore not obtained in any areas of the above analysis. Trends wore found in the expocted directions, but were not signiflcent at the .05 level. 


\section{Opinion Sheot}

The purpose of this instrument was to obtain information from the subjects themselves as to their understanding and evaluation of the project. Each of the five questions were studied separately for purposes of analysis.

Question No. 1: Percentile scores were obtained on the total number of subjects involved as to the accuracy of their response. Ninetyseven percent of all subjects responded appropriately. Such a percentage would indicate that the orientation procedures were quite adequate as that only $3 \%$ of the subjects misunderstood whether or not they were receiving detention counseling.

Question No. 2: On this response, subjects were requested to rato their own "treatment" group $\left(\mathrm{E}_{1}, \mathrm{E}_{2}, \mathrm{orC}_{1}\right)$ on a scale from 1 through 5 . A rating of 5 indicating the mst positive response possible and with 1 being the lowest possible. A breakdown of mean scores obtained are shown in Table XXI and Figure IV. Outcome of data analysis is indicated in Tables XXII and XXIII.

The data analysis reveals that there were significant differences among the "diagnostic" groups and among the treatment groups, but not for the interaction effects.

Question No. 3: This question dealt with how the subjects felt toward the "other" group. They wero asked to rate the group they were not assigned to (or so believed) on a scale from I through 5, with a rating of 5 indicating the most positive possible response. Mean scores for this item are show in Table XXIV and illustrated in Figure $\nabla$. Outcome of the data analysis is indicated in Tables XXV and XXVI. 
TABIE XXI

"Diagnostic"
Groups

(A) 1-6 days

(B) 7-14 days

(c) 15 days or more

Colum Means
$E_{1}$ Treatment

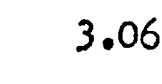

$E_{2}$

Social Interaction

3.61

3.37

3.31

3.75 $\underset{\text { Control }}{\mathrm{C}_{7}} \quad$ Row

\begin{tabular}{l|l}
3.65 & 3.44 \\
3.42 & 3.40 \\
3.93 & 3.66 \\
\hline 3.67 & 10.50
\end{tabular}

Table XXI: Mean scores obtained from Question No. 2 of the Opinion Sheet.

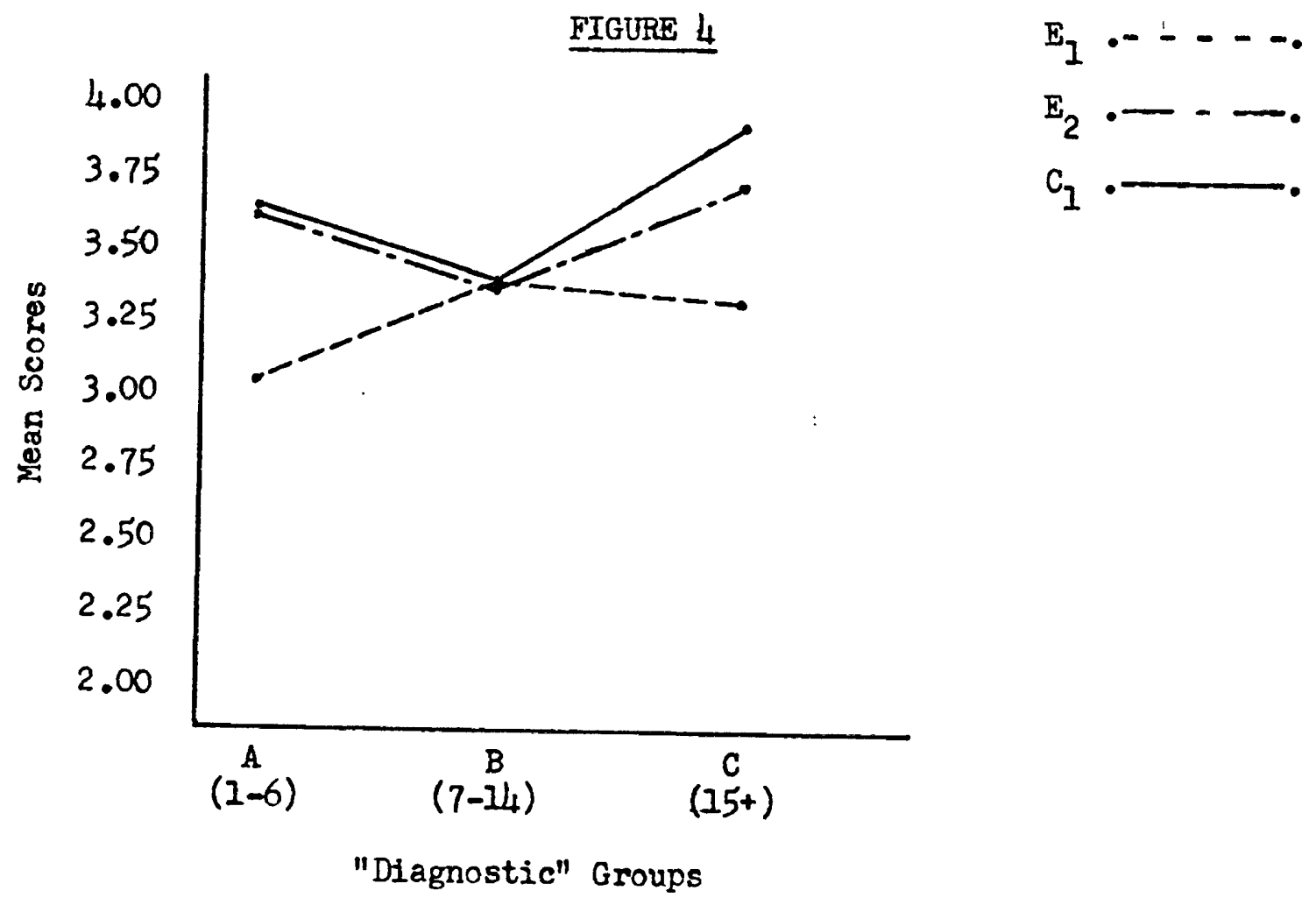

Figure 4: Illustration of the mean scores obtained from Question No. 2 of the Opinion Sheet. 
TABLE XXII

\begin{tabular}{|c|c|c|c|c|}
\hline Source & $s^{2}$ & df & $\begin{array}{c}\text { Mean } \\
\text { Square }\end{array}$ & F \\
\hline A ("Diagnosis") & .12 & 2 & .06 & $2.00 *$ \\
\hline B (Treatment) & .26 & 2 & .13 & $4.33 *$ \\
\hline AxB ("Diagnosis" $x$ Treatment) & .12 & 4 & .03 & 2.00 \\
\hline Error & 7.14 & 238 & .03 & . \\
\hline
\end{tabular}

Table XXII: Results of a $3 \times 3$ ANOVA performed on the mean scores obtained from Question No. 2 of the Opinion Sheet.

TABLE XXIII: Results of a multiple range test with unequal groups applied to the differences between "diagnostic" means and between treatment means obtained via Question No. 2 of the Opinion Sheet.

Any two means not underscored by the same line are significantly different. Any two means underscored by the same line are not significantly different.

\begin{tabular}{|l|ccc|}
\multicolumn{1}{c}{} & $B(7-14)$ & $A(1-6)$ & $C(15+)$ \\
\hline $\bar{X}$ & 3.40 & 3.44 & 3.66 \\
$n$ & 43 & 180 & 43 \\
\hline
\end{tabular}

(1)

(3)

\begin{tabular}{|c|c|c|c|}
\hline & $\frac{E_{1}}{\text { (CounseIing) }}$ & $\begin{array}{c}E_{2} \\
\text { (Social Interaction) }\end{array}$ & $\underset{\text { (ControI) }}{\mathrm{C}_{I}}$ \\
\hline$\overline{\mathrm{X}}$ & 3.26 & 3.58 & 3.67 \\
\hline $\mathrm{n}$ & 89 & 87 & 90 \\
\hline
\end{tabular}


TABLE XXIV

\section{"Diagnostic" Groups}

(A) 1-6 days

(B) $7-14$ days

(c) 15 days or
more

Column Means

\begin{tabular}{ccc|c}
$\begin{array}{c}E_{I} \\
\text { Treatment }\end{array}$ & $\begin{array}{c}E_{2} \\
\text { Intecial }\end{array}$ & $\begin{array}{c}C_{1} \\
\text { Control }\end{array}$ & $\begin{array}{c}\text { Row } \\
\text { Means }\end{array}$ \\
3.09 & 2.77 & 3.60 & 3.15 \\
2.75 & 2.74 & 3.42 & 2.97 \\
2.87 & 2.92 & 3.80 & 3.19 \\
\hline 2.90 & 2.81 & 3.60 & 9.31
\end{tabular}

Table XXIV: Mean scores obtained via Question No. 3 of the Opinion Sheet.

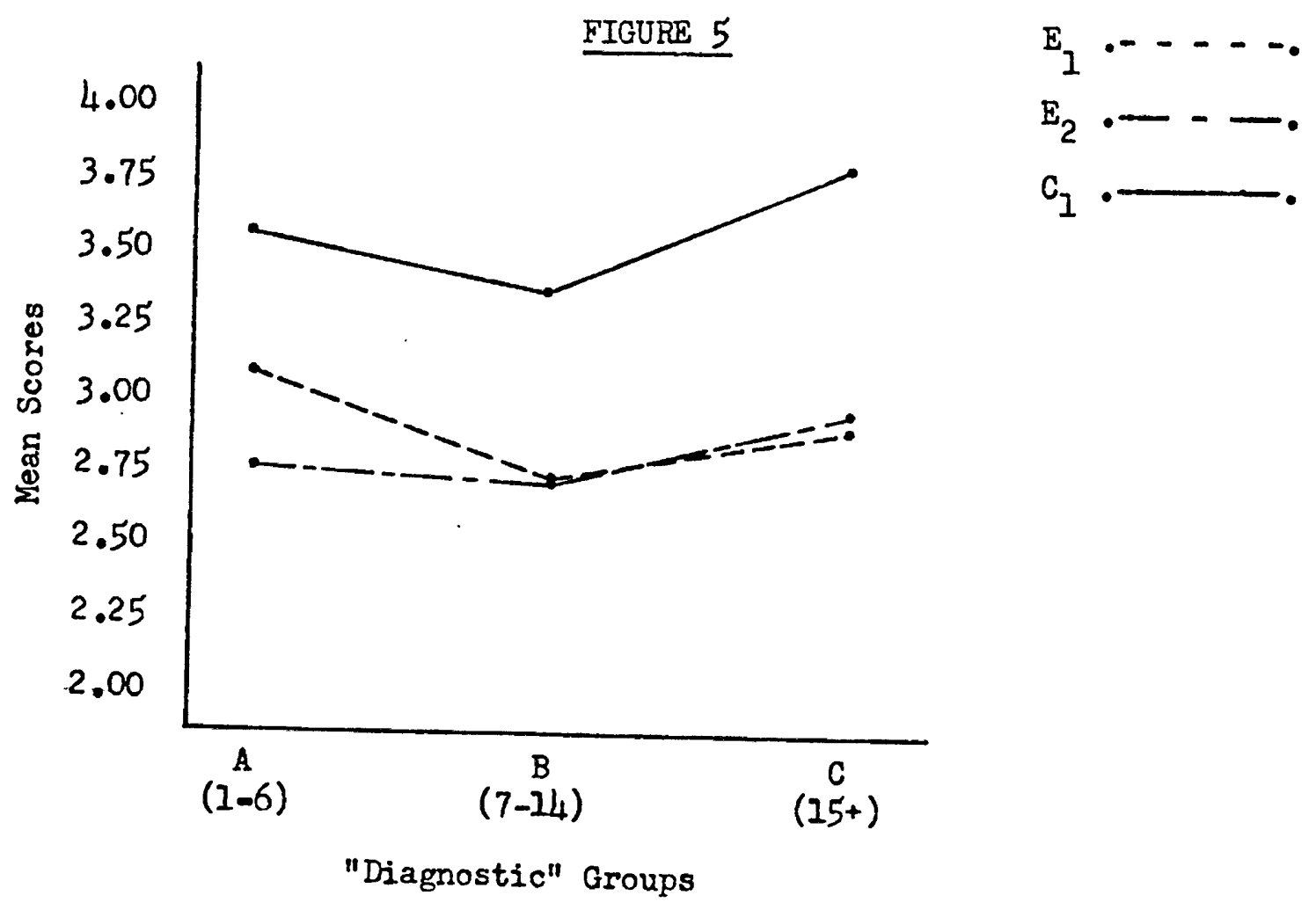
Figure 5: Illustration of the mean scores obtained via Question
No. 3 of the Opinion Sheet. 
TABLE XXV

\begin{tabular}{|c|c|c|c|c|}
\hline Source & $s^{2}$ & $d f$ & $\begin{array}{l}\text { Mean } \\
\text { Square }\end{array}$ & $\mathbf{F}$ \\
\hline A ("Diagnosis") & .08 & 2 & .04 & $2.00 *$ \\
\hline B (Treatment) & 1.12 & 2 & .56 & $28.00 *$ \\
\hline AXB ("Diagnosis" $x$ Treatment) & .05 & 4 & .01 & .50 \\
\hline Error & 4.76 & 238 & .02 & \\
\hline
\end{tabular}

Table XXV: Outcome of the $3 \times 3$ ANOVA performed on the mean scores obtained from Question No. 3 of the OpInion Sheet.

TABLE XXVIs Results of a multiple range test with unequal groups applied to the differences between "diagnostic" means and between treatment means obtained via Question No. 3 of the Opinion Sheot.

Any two means not underscored by the same line are significantly differont. Any two means underscorod by the same line are not significantly different.
(1)
(2)
(3)

\begin{tabular}{|c|rrr|}
\hline \multicolumn{1}{|c}{} & $B(7-14)$ & $A(1-6)$ & $C(15+)$ \\
\hline $\bar{x}$ & 2.97 & 3.15 & 3.20 \\
& 43 & 180 & 43 \\
\hline
\end{tabular}

(1)

(2)

(3)

\begin{tabular}{|c|ccc|}
\multicolumn{1}{c}{} & $\begin{array}{c}\mathrm{E}_{2} \\
\text { (Social }\end{array}$ Interaction) & $\begin{array}{c}\mathrm{E}_{1} \\
\text { (Counseling) }\end{array}$ & $\begin{array}{c}\mathrm{C}_{1} \\
\text { (Control) }\end{array}$ \\
\hline $\mathrm{x}$ & 2.81 & 2.90 & 3.61 \\
$\mathrm{n}$ & 87 & 89 & 90 \\
\hline & $\mathrm{E}_{2}$ & $\mathrm{E}_{1}$ & $\mathrm{C}_{1}$
\end{tabular}


This analysis indicated that statistically significant difforences were present among both the treatment groups and the "diagnostic" groups. Significant differences were not present for the interaction effects. Question No. 4: This item was employed to test whether or not the childron viewed "counseling" or social interaction as moro beneficial. They were asked to rate their "counselor" on a scale of 1 to.5, with 5 again being the most positive response possible. The control group $\left(c_{1}\right)$, of course, did not respond to this item. Mean results are shown in Table XXVII and in Figure 6. The outcome of the data analygis is indicated in Table XXVIII.

The analysis indicates statistically significant differences among treatment groups and for the interaction offects. Significant differences were not found among "diagnostic" groups.

Question No. 58 Percentile scores were obtained for the total number of subjects and for esch treatment group as to their preference. Serenty-one percent of all subjects $\left(C_{1}=49 \% ; E_{2}=79 \% ; E_{1}=85 \%\right)$ indicated that thoy would prefer to have a detention counselor.

\section{TABLE XXVII}

\begin{tabular}{|c|c|c|c|c|}
\hline \multicolumn{2}{|c|}{$\begin{array}{l}\text { "Diagnostic" } \\
\text { Groups }\end{array}$} & Treatment & $\begin{array}{c}\mathrm{E}_{2} \\
\text { Social } \\
\text { Interaction }\end{array}$ & $\begin{array}{l}\text { Row } \\
\text { Meane }\end{array}$ \\
\hline (A) & $1-6$ days & 3.16 & 3.02 & 3.09 \\
\hline (B) & $7-14$ days & 3.33 & 2.68 & 3.00 \\
\hline (c) & $\begin{array}{l}15 \text { days or } \\
\text { more }\end{array}$ & 3.12 & 3.33 & $3 \cdot 22$ \\
\hline & olumn Mern: & 3.20 & 3.01 & \\
\hline
\end{tabular}

Table XXVII. Mean scores obtained from Question No. 4 of the Opinion Sheet. 


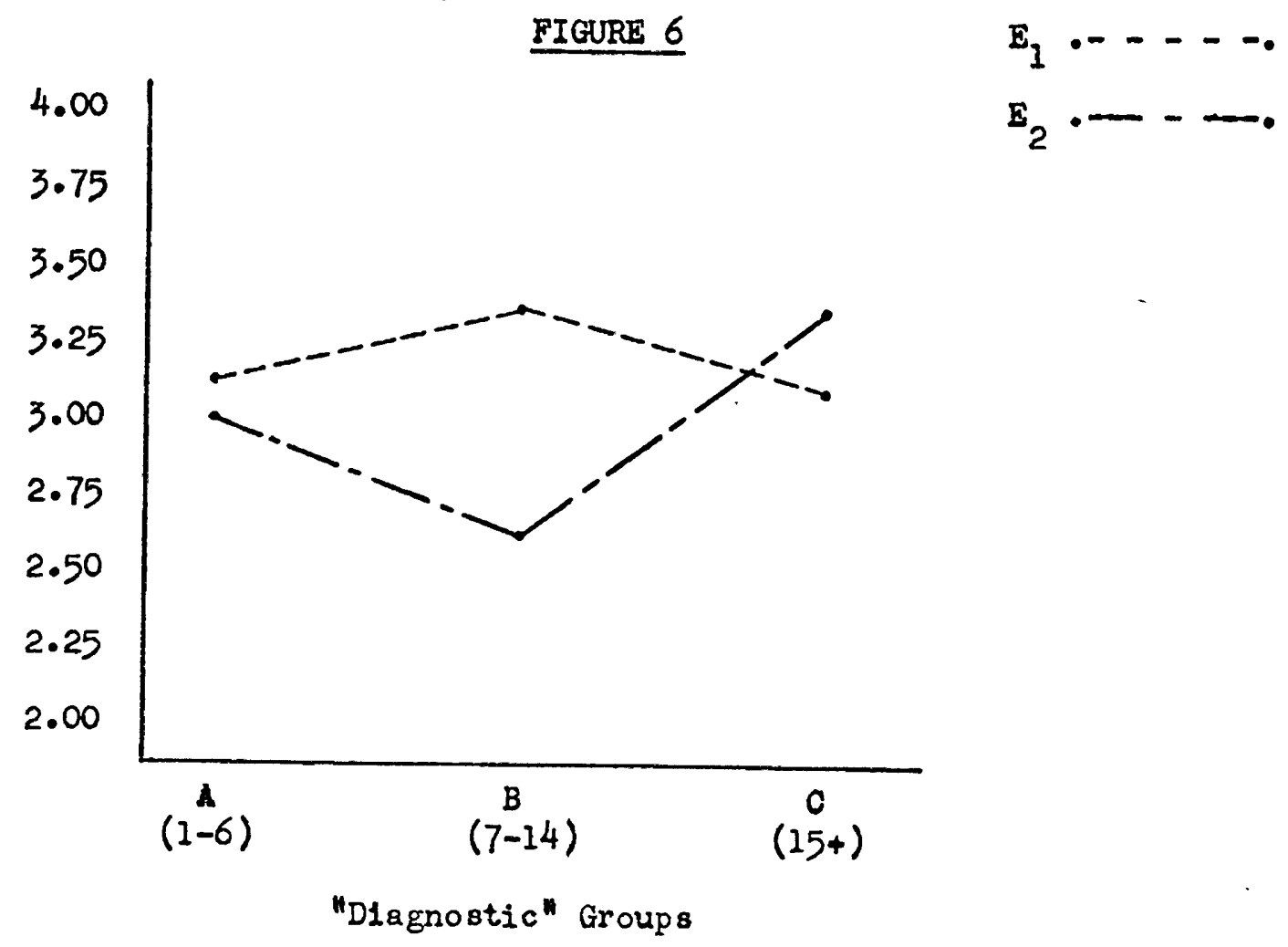

Figure 6: Illustration of the mean scores from Question No. 4 of the Opinion Sheet.

\section{TABLE XXVIII}

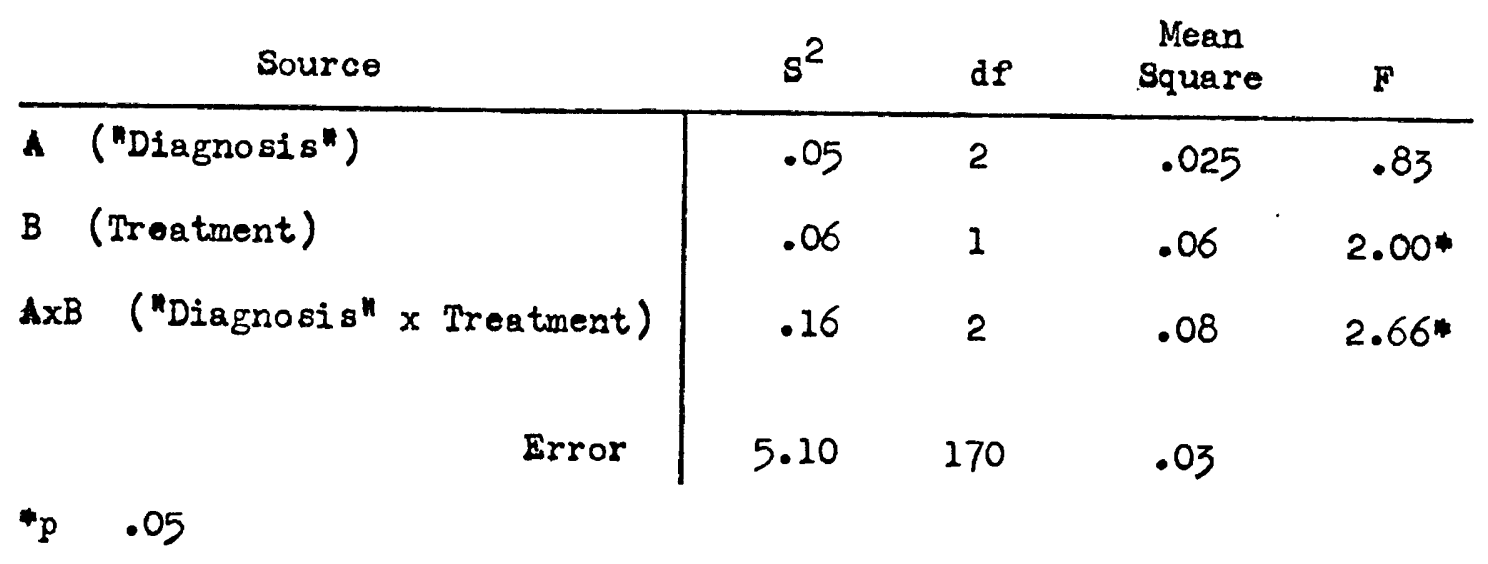

Table XXVIIIs Outcome of $2 \times 3$ NNOVA utilizing mean scores from Question No. 4 of the Opinion Sheet. 


\section{DISCUSSION AND CONCLUSIONS}

\section{Behavior Activity Inventory}

Data analysis of the Social Activity category indicated support for the hypothesis that social activity among detained children will increase with length of stay. Support was not found for the hypothesis that detention counseling would result in an increase of social activity while in detention. Therefore, one may safely assume that the level of social activity among children in detention increases with length of stay, but this increase is not related to whether or not a child was involved in individualized detention counseling.

It should be pointed out that while there was a significant increase in social activity with length of stay, the increases took place at a very low level. Mean scores of those staying in detention 15 or more days did not go beyond the Parasocial Behavior Level, the second lowest level of social activity. This level of activity is described as "behavior directed towards another group or individual without further involvement with that group or person." In consideration of this, one should be quite guarded in the interpretation of this finding. The low nature of the mean scores would tend to indicate that children in a detention facility keep primarily to themselves and are only moderately more comfortable socially with the passage of time.

Freedom of Movement data anelysis indicated significant differences regarding length of stay only.

The hypothesis that subjects receiving detention counseling would exhibit less restriction of movement than subjects not receiving such counseling was not supported. 
The hypothesis that children who were detained for longer periods of time would have exhibited more freedom of movement was not supported. The results indicate that there is, in fact, a significant difference in the opposite direction. In other words, the longer a child is detained, the more his freedom of movement is restricted due to minor rule infractions. One should be careful not to place a high degree of importance on this finding without considering the nature of the mean scores. The overall mean scores of all groups indicate that the level of restriction was rather low ( 1.3 on a scale of 1 through 5 ). This would indicate that while detained children increase their level of "unacceptable" behavior as they stay longer, this level is within "normal" limits. The low level of the mean scores tells us that this "behavior" is typical of things one could expect from most adolescents in any household (putting feet on furniture, talking back to peers, using bad manners, etc.). The label of being "in detention" tends to bias others towards believing that this type of child is frequently engaged in "severely" unacceptable behavior, and this is not supported by these findings under these conditions. Analyzing Negative Behavior data resulted in significant findings regarding the effects of counseling, the length of stay, and the interaction effects.

The hypothesis that children not receiving "detention counseling" would exhibit significantly more negative behavior than others was supported.

The hypothesis that subjects who were in detention for longer periods of time would exhibit significantly less negative behavior was not supported. Significant differences in the opposite direction were found. Significant differences found for the interaction effects indicate 
that the variables of "detention counseling" and "length of stay" are co-dependent in respect to their relationship to "negative behavior." The data suggests that "social interaction" and "Individualized counselIng" resulted in less negative behavior for children detained 6 days or Iess.

The mean scores obtained on the negative behavior category had more variation and were representative of the middle ranges of the scale. Therefore, one may rely more accurately upon interpretations regarding the negative behavior category.

\section{Attitudinal Rating Scale}

Analysis of results obtained from the initial ratings were not significant, as was expected in view of the random assignment to groups upon admission.

Nor were significant differences found when analyzing the results of the final rating.

The hypothesis that subjects receiving detention counseling would receive significantly higher ratings than those not receiving such counseling was not supported. Nor was there support for the hypothesis that the longer a child stayed in detention, the higher the rating he would obtain. This would tend to indicate that from the point of view of the staff involved, there were no significant differences among detained children in reference to relating to authority, regardless of how Iong the child had been in detention or whether or not the child had received detention counseling.

\section{Opinion Sheet}

Question No. I: As reported in the results section, $97 \%$ of all 
subjects responded as expected. The $3 \%$ of inappropriate responses are attributed primarily to children who were only lodged overnight and, therefore, not fully involved in the program. One may safely assume that the orientation of subjects in respect to detention counseling was adequate and that the subjects themselves understood the difference.

Question No. 2: The hypothesis that children receiving detention counseling would rate their own "treatment" group significantly higher than would children not receiving counseling rate their own "treatment" group was not supported. A significant difference was in fact present in the opposite direction. This indicates that the children viewed groups other than their own as being more desireable.

The hypothesis that children detained for longer periods of time would rate theis own "treatment" group significantly higher than would those detained for shorter periods was supported. This suggests that the longer a child was detained the more supportive he felt towards the group he was in regardless of the nature of that group.

Question No. 3: Significant "diagnostic" and "treatment" effects were found, but none for the interaction effects. The hypothesis that length of stay would have no significant effect on how one rated the "other" group was not supported. Length of stay, in fact, did significantly alter a subject's rating of the "other" group. The data indicates that subjects rated the "other" group significantly lower than their own group when detained from 7 to 14 days. This suggests that these results were temporary in nature.

Support was found for the hypothesis that those believing they were receiving detention counseling would rate the "non-counseling" group signfficantly lower than would the "non-counseling" group rate the "counsel- 
ed" group. This indicates that those who felt they were receiving detention counseling viewed that situation as the more desireable of the two possibilities.

Question No. 4: Significant differences were found for treatment groups and interaction effects, but not for "diagnostic" groups.

The hypothesis that the $E_{I}$ group would rate their counselor significantly higher than the $E_{2}$ group was supported. This would lead us to belleve that those receiving detention counseling saw their counselors as more helpful than did those in the social interaction group. Looking closer, however, at the interaction effects one can see that this statement holds true only for children who were detained less than 15 days (Groups $A$ and $B$ ). Children who were detained for more than 15 days tended to rate the "Placebo" counselor slightly higher. This suggests that this finding may also be temporary in nature.

Question No. 5: As indicated previously, 71\% of all subjects indicated that they would prefer to have a detention counselor. The control group appeared rather neutral on the issue $\left(C_{1}=49 \%\right)$, whereas, the social interaction group $\left(\mathrm{E}_{2}\right)$ and the "counseling" group $\left(\mathrm{E}_{1}\right)$ indicated fairly strong support. $E_{1}=85 \%$ and $E_{2}=79 \%$.

\section{Length of Stay}

In reference to Length of Stay a number of interesting and suggestive results were obtained. The data indicates that the longer the child stays in a detentional facility the higher the incidence of negative behavior, the higher the extent of disciplinary restrictions, and the higher the degree of social involvement with others. One would normally expect such findings considering that, typicaliy, the child with more extensive emotional problems tends to act out negative behavior and requires 
a higher degree of external controls (Nelson, 1972). Care must be taken when interpreting these results, due to the mean score values. Regarding the restricted freedom of movement and the social activity scales, mean scores indicate very low levels. Therefore, even though significant increases were present, children exhibited low levels of social involvement and very low levels of disciplinary restrictions. Care should be taken against concluding that detentional facilities are detrimental to the child's welfare. These findings do not support or deny such a conclusion. Further study is certainly necessary to adequately weigh the "treatment" benefits against the effects of increased length of stay. The present trend to maintain length of stay in a detention facility to a minimum (Adams, et al, 1973), is moderately supported by the above mentioned findings. The central issue would appear to be the quality rather than quanity of the detention experience.

\section{Behavior Control}

In dealing with the Control of Behavior in a detention facility, the data also warrants further consideration. Data analysis suggests that the combined process of individualized detention "counseling" and group process techniques may provide a greater degree of behavior control in this particular type of setting. The primary supportive indicator of this statement was provided by the Behavior Activity Inventory instrument (Negative Behavior). The Negative Behavior Scale is seen as the most sensitive of the scales used and data obtained, therefore, as dependable. These results suggest that the social interaction with a counselor is equally as meaningful as the counseling itself. It may very well be that the individual attention the child receives is the critical factor. It 
should also be noted that this effect leveled off after 15 days and was no longer significant. This, of course, suggests that the individual attention factor may not be as critical in a Ionger term facility. This is only a possibility that is suggested by the findings and requires further verification.

A reminder, however, that the other category of the Behavior Activity Inventory designed to evaluate control of behavior (Freedom of Movement) did not support the findings of the negative behavior category. Even though the freedom of movement scale is seen as less sensitive, this difference certainly warrants further study.

Material obtained via the rating scale indicated that staff observed no behavior changes that were attributable to the effects of the "counseling" or "individual attention" given the subjects. The data does show that the trends were in line with findings obtained from the negative behavior scale, and it is possible that a more sensitive instrument here might provide more meaningful data. It should be noted that poststudy comments by staff indicated a positive regard for this type of approach, and a higher level of morale. Previous Iiterature (Coffey, 1974; GIasser, 1964) and these factors indicate that consideration and study of these factors certainly deserve attention.

Analysis of the childrea's oplnions generally lent support for combining individual counseling with group counseling. Again the predominant finding was that the social interaction factor was just as important as the counseling per se. Item No. 4 was an exception to this. Counseling was preferred over social interaction for children detained less than 15 days. Social interaction was preferred after 15 days in detention. Although the results obtained from the opinion sheet were supportive of the 
general hypothesis, it is felt that more verification is necessary. This instrument is seen as the least reliable of the three utilized. The reason for this being that children of this age group are highly impressionable and concentrate a great deal of their efforts towards getting released from detention (Ohlin, 1973). Therefore, it is possible that their responses reflect a desire to please staff and, consequently, may be falsified.

\section{Summary}

The review of literature identified three major areas contributing to a lack of research relative to detention facilities (Adams, et al, 1973; Caven, 1962; Robinson, 1960; Quay, 1965). These factors presented no problems in the present study. Administrative co-operation was easily obtained. Detention home staff were found to be highly qualified and competent individuals. Shortness of stay lent itself well to an emolrical research design. The lack of research of detention facilities appears unnecessary and unwarranted based on the experiences of this study.

The general hypothesis of this thesis: Individualized "counseling" by detention home staff will result in less antisocial behavior exhibited by detainees and the degree of change will vary according to length of stay, was partially supported. Partial support was obtained on two out of three instruments utilized (Behavior Activity Inventory and Opinion Sheet). Initial predictions that individual "counseling" would be more beneficial than "social interaction" was not upheld. The majority of results indicated that social interaction resulted in less antisocial behavior than did the counseling or control groups.

In respect to length of stay, these findings applied to children 
who were detained less than 15 days. Beyond 15 days neither social interaction nor counseling consistently effected antisocial behavior. Initial predictions that antisocial behavior would reduce with length of stay was not upheld. The findings indicate that antisocial behavior tends to increase with length of stay.

In summary, the data herein supports the position that individualized "attention" is beneficial towards controling behavior of children in a detention facility. "Attention" appears to be a more important factor than does "counseling"; however, further study of this issue is necessary. The issues of "attention" and "counseling" are important considerations of dealing with children detained less than 15 days. Beyond 15 days their importance is not as clear and it appears doubtful that these results can be generalized to the long term institutions. The findings of this study support the rationale of combining group counseling techniques with increased "attention" for juveniles in short term institutions. 


\section{BIBLIOGRAPHY}

Adams, Gary B.; Carter, Robert M.; Gerletti, John D.; Pursuit, D.G.; Rogers, Percy G., Juvenile Justice Management, (Springfield, Illinois: Charles C. Thomas, 1973).

Adams, S., "Effectiveness of Interview Therapy: An Interim Assessment of the PICO Project," Research Report \#20, California Youth Authority, Division of Research, 1961.

Allen, Harry E.; Eynon, Thomas G.; Reckless, Walter C., "Measuring Impact of a Juvenile Correctional Institution by Perceptions of Inmates \& Staff," Journal of Research in Crime \& Delinquency, 1971 (Jan), Vol. 8, No. 1, pp. 93-107.

American Correctional Association, 103rd Congress of Correctional Proceedings, Seattle, Washington, Aug • 12-Aug. 17, 1973.

Amos, William E.; Manella, R.L., and Southwell, Marilyn A., Action Programs for Delinquency Prevention, (Springfield, Illinois: Thomas Books, 1965).

Amos, William E.; Manella, Raymond L., Readings in the Administration of Institutions for Delinquent Youth, (Springfield, IIIinols: Charles C. Thomas, 1965).

Amos, William E.; Manella, Raymond L., Delinquent Children in Juvenile Correctional Institutions, (Springfield, Illinois: Charles C. Thomas, 1966).

Amos, William E.; Wellford, Charles F., Delinquency Prevention, (New Jersey: Prontice-Hali, Inc., 1967).

Ariessohn, Richard M.; Closson, Frederick I., "Alternatives to Detention", California Youth Authority Quarterly, 1971 (Winter), Vol. 24, No. 4, pp. I7-26.

Averill, Stuart C.,; Cadman, William H.; Craig, Leita P.; Linden, Robert E., "Group Psychotherapy with Young Delinquents: Reports from a Residential Treatment Center." Bulletin of the Menninger Clinic, 1973 (Jan), Vol, 37(1), pp. 1-70.

Bakal, Yitzhak, Closing Correctional Institutions, (Lexington, Mass.: Lexington Books, 1973).

Berne, E., Group Treatment, (New York: Grove Press, Inc., 1966). 
Bigelow, Douglas A.; Driscoll, Richard H., "Effect of Minimizing Coorcion on the Rehabilitation of Pri soners," Journal of Applied Psychology, 1973 (Fob), Vol. 57(1), pp. 10-14.

Breed, Allen F., "The Youth Authority in 1972," California Youth Authority Quarterly, 1972 (Fall), Vol. 25, No. 3, pp. 3-11.

Carter, Robert Melvin, (Edited by Carter; Glasser, Daniel; Wilkins, Leslie T.), Correctional Institutions, (Philadelphias Lippincott; 1972).

Cavan, Ruth S., Juvenile Delinquency, (New York: J.B. Lippincott, 1962).

Coffey, Alan, Correctional Administration: The Management of Probation, Institutions, and Parole, (Englewood Cliffs, New Jersey: PrenticeHa11, 1974).

Cowden, James E.; Bassett, H. Thomas, "A Comparison of Reformatory Inmates Committed Directly by the Court with those Transferred from Juvenile Institutions, Journel of Clinicel Psychology, 1972 (Apr), Vol. 28(2), pp. 214-215.

Cull, John; Hardy, Richard E., Applied Psychology in Law Enforcement and Corrections, (Edited by Hardy and Cull), (Springfiold, Illinolsi Thoma 8, 1973).

Davidoff, Eugeno; Notetzel, Elinor S., The Child Guidance Approach to Juvenile Delinquency, (New York: Child Care Fublications, 1951).

Edward8, Allen L., Experimental Design in Psychological Research, (Now York: Holt, Rinehard, \& Winston, 1972).

Falrweather, Goorge W., Social Psychology in Troating Mental Illneas,

(New York: Wiley and Sons, Inc., 1964).

Fairweather, George W., Methods For Experimental Social Innovation, (Now York: John Wley and Sons, Inc., 1967).

Fox, Vernon Brittain, Introduction to Corrections, (Englowood Cl1ffs, New Jersey: Prentice-Hall, 1972).

Freeman, Howard E.; Weoks, H.A., Mnalyais of a Program of Treatment of Dolinquent Boys," Amorican Journal Soc., 1962 (July), Vol. 1, pp. 56-61.

Friedlander, Kate, The Psychoanalytic Approach to Juvenile Delinqueacy, (Now York: International Univ. Press, Inc., 1949).

Giallombardo, Rose, Juvenile Delinquency, (Now Yorks John Wiley \& Sons, Inc., 1966).

Gibbens, T., Trends in Juvenile Delinquency, Geneval World Health Organization, 1961. 
Gibbons, Don, C., Changing the Lawbreaker: The Treatment of Delinquents \& Criminals, (Englewood Cliffs, New Jersey: Prentice-Hally, 1965).

Glasser, Daniel, The Effectiveness of a Prison and Parole System, (Indlanapoits, Indiana: Bobbs Merrill, 1964).

Hardy, R.E.; Cull, John, Law Enforcement and Correctional Rehabilitation, (Edited by John G. Cull and Richard E. Hardy), (Springfield, Illinots: Thomas, 1973).

Hardy, Richard E., Introduction to Correctional Rehabilitation, (Springfield, Illinols: Thomas, 1973).

Hartinger, Walter, Corrections: A Component of the Criminal Justice System, (By Hartinger; Eldefonso, Edward; Coffey, Alan), (Pacific Palisades, California: Goodyear Publishing Co., 1973).

Hundal, P.S.; Brar, H.S., "Measuring the Impact of Reformatory Education on the Manifest Behavior and Some Psycho-Social Aspects of Juven1le Delinquents," International Review of Applied Psychology, 1971 (Oct), VoI. 20(2), pp. 149-156.

Jones, Howarä, Reluctant Rebels, (New York: Associated Press, 1960).

Kramer, C.Y., "Extension of Multiple Range Tests to Group Means with Unequal Numbers of Replications," Biometrics, 1956, Vol. 12, pp. 307-310.

Kraraceus, William C., The Communtty and the Delinquent, (New York: World Book Co., 1954).

Lewis, William B., "Counseling Programs in Juvenile Institutions," California Youth Authority Quarterly, 1972 (Fall), Vol. 25, No. 4, pp. 8-I2.

MacIver, Robert M., The Prevention and Control of Delinquency, (New York: Atherton Press, 1966).

Menninger, Karl, The Crime of Punishment, (New York: The Vikdng Press, 1968).

Moos, Rudolf H., "Differential Effects of the Social Climates of Correctional Institutions," Journal of Research in Crime \& Delinquency, 1970 (Jan), Vol. 7, No. I, pp. 71-82.

National Council on Crime \& Delinquency, Standerds and Guides for the Detention of Children and Youth, (New York: I96I).

National Research and Information Center on Crime \& Delinquency, Current Projects in the Prevention, Control, and Treatment of Crime and Delinquency, (Now York, VoI. I-VI, 1961-65). 
Nelson, Henry, When Mother is a Prefix: New Directions in Youth Correction, (New York: Behavioral Publications, 1972).

Norman, Sherwood, Detention Practice, (New York: National Probation and Parole Association, 1960).

Ohlin, Lloyd E., Prisoners in America, (Englewood Cliffs, New Jersey: Prentice-HaII, 1973).

Orland, Leonard, Justice, Punishment, Treatment: The Correctional Process, (New York: Free Press, 1973).

Pilnick, Saul; Clapp, Neale W., "The Essexfields Concept: A New Approach to the Social Treatment of Juvenile Delinquents," J. Appl. Behav. Sc1., 1966, 2,1, Jan/Mar, pp. 109-129.

Quay, Herbert C., Juvenile Delinquency - Research and Theory, (New York: D. Van Nostrand Co., Ine., 1965).

Robison, Sophia M., Juvenile Delinquency - Its Nature and Control, (New York: Holt, Rinehart and Winston, 1960).

Roucek, Joseph, Juventle Delinquency, (New York: Philosophical Library, Inc., 1958).

Sagarin, Edward; MacNamara, Donal E.J., Interamerican Congress of CrimInology, 2d, Caracas, 1972. Corrections: Problems of Punishment \& Rehabilitation, (New York: Praeger, 1973).

Scott, Edward M., Criminal Rehabilitation....With and Without the Walls, (Edited by Edward M. Scott \& Kathryn L. Scott), (Forward by George A. Van Hoomissen), (Springfield, Illinois: Thomas, 1973).

Slavson, S.R., Introduction to Group Therapy, (New York: Commonwealth Fund, 1943).

Smith, Alexander B.; Berlin, Louls, Treating the Criminal Offender: Issues and Problems, (Dobbs Ferry, New York: Oceana, 1974, IX, pp. 372).

Sinth, John E., "The Effects of Group Counseling on the Behavior of Juvenile Probationers," Dissertation Abstracts International, 1973 (Feb), Vol. 33(8-A), 4103 .

State of California: Department of the Youth Authority, Current Status Report of Research Activities, 1960-1969.

Stein, Franklin, "Comminity Rehabilitation of Disadvantaged Youth," American Journal of Occupational Therapy, 1972 (Sept), Vol 26(6), pp. 277-283.

Street, David; Perrow, Charles; Vinter, Robert D., Organization for Treatment, (New York: The Free Press, 1966). 
Teeter 8, Negley K.; Reinemann, John 0., The Challenge of Delinguency,

(New Jersey, Prentice-Hall, Inc., 1955).

Truax, Charles B., "Percoived Therapeutic Conditions and Client Outcome," Oomparative Group Studies, 1971 (Aug), Vol 2(3), pp. 301-310.

United Nations, Comparitive Survey of Juvenile Delinguency - Part $1_{2}$ North Americe, (New Yorki 1958).

U.S. Department of Justice (LEAA), New Approaches to Diversion and Treatment of Juvenile "Offenders," Criminal Justice Monograph, June, 1973.

Wheeler, Stanton, Controlling Delinquents, (New York: John Wiley and Sons, Inc., 1968). 
Los Angeles County Juvenile hall Operation Manual Bulletin D-151 4-22-58

\section{APPENDIX I}

\section{SUBJECT DYNAMICS OF ORIENTATION}

Detention is a critical experience for all of our children, and in order that it not be a damaging one it is very important that a suitable period and method of orlentation be provided.

If a boy knows what to expect and what is expected of him, efforts to secure his cooperation will meet with more success. While proceeding along these lines in talking with the newly admitted boy, it might be useful to bear in mind that basically all activity on our part should be in his behalf just as the court action itself is in his behalf. Therefore, a proper orientation of the boy depends upon a correct orientation of the staff in the direction of helping the boy to adjust to the experience of detention without suffering emotional damage.

- In order to do this we mast manage our orfentation interview very carefully and also recognize that since our attitudes are comminicated to the children in non-verbal ways, our own feelings and attitudes are important and must be managed as well.

The orientation of the boy takes place at several levels, 1) the formal or surface level is in terms of what is said to him in a face to face interview by the counselor, 2) informally by means of what the boy feels the counselor is really commulcating by his action, manner and att1tude and which may not exactly match what is actually stated, 3) informally by means of situational cues provided by the other boys, and other staff, and the total impect of the Hall. 
Conscious recognition that these factors are present and alertness to the probability that many other elements may be involved in a dynamic interrelation will tend to make our orientation talk more objective and condition us to be sensitive to the true needs of the boy.

It is important that we try to mobilize whatever positive motivation each boy possesses and probably we should assume that each boy does have a considerable desire to do well, make a good record, etc. It is no doubt safe to say, however, that each boy is ambivalent, prone to vacillate between what a particular impulse would cause him to do and what Is the socially accepted or likely to be the adult expected thing to do, and is easily tempted, easily led, and likely to succumb to stimiation from the group.

Having these things in mind w1ll help us in our dealings with the boys since they will surely sense our attitude and our basic acceptance and belief in them. Also having these principles in mind will aid us in standing firm when boys are involved in conduct which isn't socially approved and insist that each boy exert every effort at reasonable self control.

Counselors should indicate suitable standards of conduct, but avoid lists of rules or other devices that have negative connotations and are not generally useful techniques in securing the boy's cooperation.

It may be helpful to plan the orientation as a three stage process which might be described as 1 ) the preliminary or getting acquainted stage, 2) the interviow stage, and 3) the follow-up. Such a plan makes allowances for various aspects of the problem. Frequently the 3rd step is not completed, or is overlooked entirely, due to the many daily pressures, but also, in part at least, due to lack of a conscious orientation 
plan. A follow-up simply means to see to it that as far as possible everything essential has been covered and checked as to whether previous materlal has been fully understood and assimilated. The follow-up interview might be lengthy or brief, depending on what remained to be done and would be an interesting way to check on how effective the first two stages of the process had been.

The preliminary, or getting acquainted stage is also often not utilized as fully as it could be. Its importance is pretty generally recognized, but in some cases when intake is very heavy the boys are handled in merely a routine and mechanical way, whereas the period should be used to make pertinent observations, put the boy at ease and prepare the ground for the direct interview.

The interview itself can be most effective if it can be so managed that the boy has an opportunity to respond and to state his feelings, etc. By allowing the boy to express how he feels, the counselor can not only obtain some idea of the kind of boy he is dealing with and how best to help him, but getting a chance to tell someone his side of the story will be beneficial in itself in terms of relleving tension, etc.

Throughout the admission procedure and during the early hours and days of the boy's stay, it is reasonable to expect that many boys will be angry and resentful, excited or frightened, guilty and upset, plus various combinations of these reactions. Our aim should be to admit the boy matter of factly without any countering hostility or excitement on our part. A calm and objective manner will tend to reduce most of the overt hostility and indirectly serve to prepare the way for the actual orientation talk. During this period very little "lecturing" is advisable. Caring for the boy's basic needs for food, shelter, etc., is not only necessary at 
this point, but by meeting these needs, the boys will realize that we are interested in their welfare and are not worried about how aggressive they are. At this stage they may not be very receptive to a direct interview anyway. In the face of our steady and "non-punishing" attitudes, the boys will almost invariably calm down. Much of their unpleasant and undesirable behavior, particularly at this time, can be understood as a defense and in some cases a defense against underlying anxieties which may not be obvious from their surfact behavior. This is probably true even of boys that have been in the Hall several times. In any case, it may not be appropriate to delve too deeply into this area, but rather to be alert to, the possibilities of the situation, and if very unusual behavior is noted, proper referral should be made through the usual channels.

\section{Counseling Interviews}

It is important that all children detained at Juvenile Hall should have frequent opportunities to talk privately to the counselors in charge of their respective units. Such brief, private interviews permit the chld to ask questions, to obtain advice and to discuss problems in regard to his immediate situation. They also enable the counselor to gain a better understanding of the attitudes and behavior of the child.

For this purpose, it is the responsibility of each counselor who is in charge of a group during the day to arrange for brief, individual counseling interviews with as many children as time permits. As a rule, it should be possible for several counseling interviews to be conducted during the morning and afternoon shifts so that every member of the group should have a private conference with one of the counselors in charge of his unit more than once during the week. 
It is understood that the probation counselor must be careful not to be drawn into discussion concerning placement plans or family situations which are the concern of the child's probation officer. If necessary, questions concerning court proceedings, plans for placement, etc., may be transmitted to the child's probation officer through a Juvenile Hall deputy probation officer. It is essential that all interviews be handled in such a way that the children may speak freely and that others within the group will not be aware of anjthing that may have been reported in situations involving others.

In addition to a notation on the Behavior Chart recording, the counseling interview, and any significant information derived from the interview, the interview should also be recorded in the Daily Log so that the other counselors in the unit can tell which children have been recently interviewed.

The counseling interviews held in accordance with this procedure w11l supplement the counseling which takes place continually during the day in supervising the group or in dealing with individual problems and may be especially important for children who are inclined to be timid or withdrawn and, therefore, do not come to the attention of the counselor as conspicuously as others who are more aggressive and disorderly. 
APPENDIX II

Freedom

of

Name Location

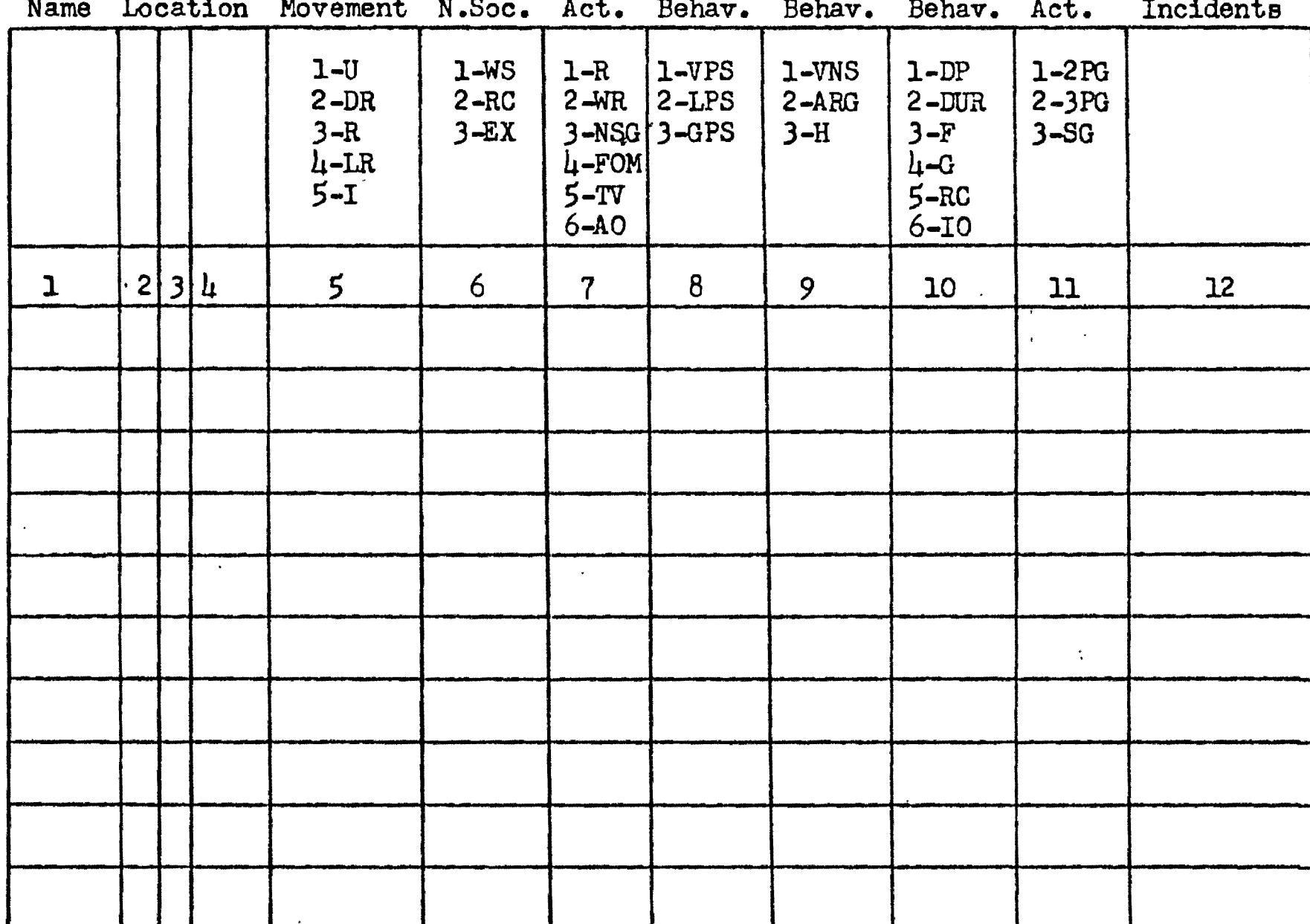

Date

Day

Time

Page

Order

$1-16$

$16-1$

\section{LOCATION KEY:}

1. CLASSROOM

2. CRAFTROOM

3. LIVING ROOM

4. GAME ROOM

5. DINING ROOM

6. KITCHEN

7. OFFICE

8. CLOTHING ROOM

9. LAUNDRY ROOM

20. NORTH BATHROOM

17. NORTH HALL

12. WEST BEDROOMS

13. EAST BEDROOMS

14. DORMITORY

15. SOUTH BATHROOM

16. SOUTH HAIL 


\section{APPENDIX III}

BEHAVIOR ASSESSMENT INVENTORY (BAI) INSTRUCTION MANUAL

Observations are to be made once a day during a recreational period. Before entering the ward, the observer is to place the following Information on the scoring sheets:
A) Day, Date and Time
C) Page Number
B) Pattern of Observation
D) Observer's Initials

The ward has been divided into geographical areas; the observer will alternately rate the ward from first to last location - that is, the pattern of observation is to be reversed on each successive day.

A. Orientation Instructions:

1) Whenever appropriate, the observer will choose a seat in a favorable, but inconspicuous, vantage point.

2) Upon entering each geographical area, record the name of each child present before applying the ratings.

3) For children located in the living room and other highly populated areas, record in the following manner: Begin with extreme left side of area and circulate around the room in a clockwise fashion until all children on the perimeter are entered; begin again from left to right until each child in the central area is recorded.

4) Maintain a passive relationship with the children.

5) Record staff only when interacting with children.

B. Scoring Instructions:

1) Behavior ratings are made after all children in the area are entered on the scoring sheet. Begin by observing the first child entered on the scoring sheet.

a) Each child is to be observed for no more than 10" before entering his behavior on the scoring sheet.

b) Always enter the location (columns 2,3,4), freedom of 
movement (col. 5), and activities (cols. 6-12) of each child.

2) If several kinds of behaviors occur simultaneously, each should be recorded.

C. Definition of Categories and Coding Format:

1) Column (I) - Child Identification

a) Enter child's name in column 1.

2) Colums (2), (3), (4) - Location

a) Enter child's initial location in column (2); subsequent locations of the child occurring within the 10" observation period are entered in column (3).

b) Enter an (X) in column (4) for children not initially observed in location area, but who have appeared since. Enter ( $Y$ ) in colum (4) for children in area who have left prior to the observation.

3) Colum (5) - Freedom of Movement

a) Enter appropriate number corresponding to initials of movement observed.

b) Categories

1) U (unrestricted):

Normal movement within the confines of the unit. Restricted only by locked doors and detention policies which apply to all children in the unit. Examples: Going from craft room to living room; going to bathroom; moving freely from room to room.

2) DR (Disciplinary Restriction to a Particular Room):

Restricted by staff from moving freely about the unit. Restricted to a particular room or from going into a particular room. Does not include restricted to his owm room. Examples: Front room probation; restriction from eraft room; etc.

3) R (Sent to Room): Child sent to his own room by staff for a short cooling off period. Purpose being for disciplinary reasons. Door remains unlocked. Examples: Sent to room for minor rale infraction; time to calm down; etc. 
4) LR (Sent to locked room):

Child locked in his room by staff because of a discipline problem. Examples: For major rule infraction, won't stay in room, etc.

5) I (Isolated):

Child is locked in an isolation room, due to his violent acting out or severe discipline problems. Does not include children who were isolated upon admission - such as institutional escapees, otc. Examples: Trying to hurt himself or others, break attempts, etc.

4) Colum (6) - Functional Non-Social

a) Enter appropriate number corresponding to initials of behavior observed.

b) Categories:

I) WS (Ward Service):

Ward Service is any behavior performed at the request of ward personnel or for the physical maintenance of the ward. Examples: Washing windows; lining up for medication; carrying equipment, chairs, tables, etc.

2) PC (Personal Care):

Activity directed by the child toward himself in order to improve his appearance or hygiene, or to facilitate his existence on the ward. Examples: Shining shoes; sewing; cleaning or straightening up bedstand, bed or locker; washing hands, showering, dressing, otc.

3) Ex (Excretory Functions): Excretory functions include all behaviors associated with urination and defecation.

5) Column (7) - Para-Social Activities

a) Enter appropriate number corresponding to the behavior observed.

b) Categories:

1) R (Reading): A child will be judged to be reading when his head and eyes are oriented in the direction of commonly accepted reading material.

2) WR (Writing):

Writing is the conventional use of a pencil or pen 
to make marks on a commonly used writing surface. Included here are letter and note writing as well as filling out ward forms.

3) NSG (Non-Social Games):

This is defined as an activity which requires the manipulation of an object and has for the subject a socially discernible purpose of amising himself. Examples: Solitaire; playing chess alone; making drawings or designs on paper; stacking dominoes, etc.

4) FOM (Functional Object Manipulation): This is characterized by a child being singularly involved in the handling or manipulation of an object. The manipulation should be judged to have socially relevant meaning and is being used for the general purpose for which it was designed. Examples: Tuning in the TV set; sandpapering a figure; repairing objects.

5) TV (Television, Radio and Phonograph): A child will be judged to be watching. television (or listening to the radio or phonograph) in the prescence of either a specific posture response or an observable emphatic or reactive response to the television. Posture refers to a position of the body which requires some special strain to orient the hesd toward the set.

6) AO (Active Observation):

This behavior is characterized by an active and effortfui attempt to observe or view some ongoing situation in which the subject is not involved himself. Examples: Obvious attempts to listen or overhear a conversation between other children in which the subject is not a member; curiously looking into rooms or offices; role of spectator in social activities being performed by other children (e.g., ping pong, cards).

\section{6) Column (8) - Para-Social Behavior}

a) Enter appropriate number corresponding to behavior observed.

b) Categories:

1) VPS (Verbal Para-Social): This is an audible verbal response to any inanimate stimilus which is conventionally endowed with a discernible social communication (e.g., TV set, radio, and game materials such as pool cues and balls, playing cards, otc.) Note that these stimulus objects 
are neither capable of responding nor being modified by the verbal communication.

2) IPS (Iaughing Para-Social):

An audible laugh directed at an inanimate stimulus object that is conventionally endowed with a discernible social comminication role, but which is neither capable of responding nor modified by the laugh.

3) GPS (Gesture Para-Social):

This is a gesture made toward any inanimate stimulus object which is conventionally endowed with a discernible social communication role, but which is neither capable or responding nor modified by the gesture.

7) Colum (9) - Negative Verbal Behavior

a) Enter appropriate number corresponding to the behavior observed.

b) Place a () in this column if the interaction is with a staff member.

c) Categories:

1) VNS (Verbal Non-Social):

This is an audible verbal response to a non-discernible stimulus. Example: Muttering or talking to self.

2) ARG (Argumentative):

Child is engaged in attempting to get someone else to change their mind. This is done so with a minimum of emotion and when it is with staff is frequently thought of as attempting to manipulate. Examples: "Conning" someone out of their treats, manipulating staff into overlooking a rule infraction, etc.

3) H (Hostile):

Verbal encounter directed at or with one or more persons which is accompanied by a great deal of emotional aggression. Examples: Yelling at someone; screaming; cussing.

8) Colum (10) - Negative Behavior

a) Enter appropriate number corresponding to the behavior observed.

b) Categories: 
1) DP (Destroying Property):

This is defined as willfully and purposefully matilating or destroying something that is of value to someone else. Examples: Breaking a window; tearing up someones school paper; flushing a roll of toilet paper down the drain; etc.

2) DUR (Disobeying Unit Rules):

This is defined as failure to obey the rules of detention as set up by that unit. This holds for all rules and all children, regardless of time spent in detention. Examples: More than one in the office at a time; going into someone else's room; throwing food, etc.

3) F (Fighting):

This is defined as physically striking someone with intent to inflict harm. There does not need to be an exchange of blows.

4) G (Gestures):

This is a gesture directed at another person with the intent to make them mad or an an expression of negative feelings. Example: Giving someone the "finger" sign.

5) RC (Refusing to Co-Operate): This is defined as verbally or non-verbally defying what someone has asked you to do. Examples: Refusing to do unit job; not passing something at the table when asked; not moving when asked; etc.

6) Io (Interfering with Others):

This is defined as purposefully attempting to interfere with something someone else is doing. Examples: Tripping someone; grabbing the ball in a ping pong game; upsetting the checker board, etc.

9) Column (II) - Small Group Interactions

a) Under column (16) enter the appropriate number corresponding to the type of group interaction in which the subject is engaged. Place a check $(\checkmark)$ in this colum is the $S$ verbally contributes during the $10^{\prime \prime}$ period of observation.

b) Categories:

1) 2PG (Two-Person Group):

This is defined as two children engaged in social communication and includes non-verbal acts of recognition, such as waving or nodding greetings, visibly sharing jokes or similar experiences, etc. 
2) 3PG (Three or More Person Group):

This is defined as relatively close body proximity among three or more children engaged in social communication. Examples: Three children walking together; four children listening to a fifth read aloud; etc.

\section{3) SG (Social Games):}

This is an activity carried on jointly by 2-3 children with the shared purpose of diversion or entertainment. Note: Social games including four or more persons are to be rated in the 3PG category.

10) Colum (12) - Critical Incidents

a) This is a write-in category; all behaviors which cannot be properly classified under the previous categories are to be placed here. Particularly relevant here are overtly aggressive, sexual behavior, as well as relatively novel or otherwise uncommon ward behavior. 